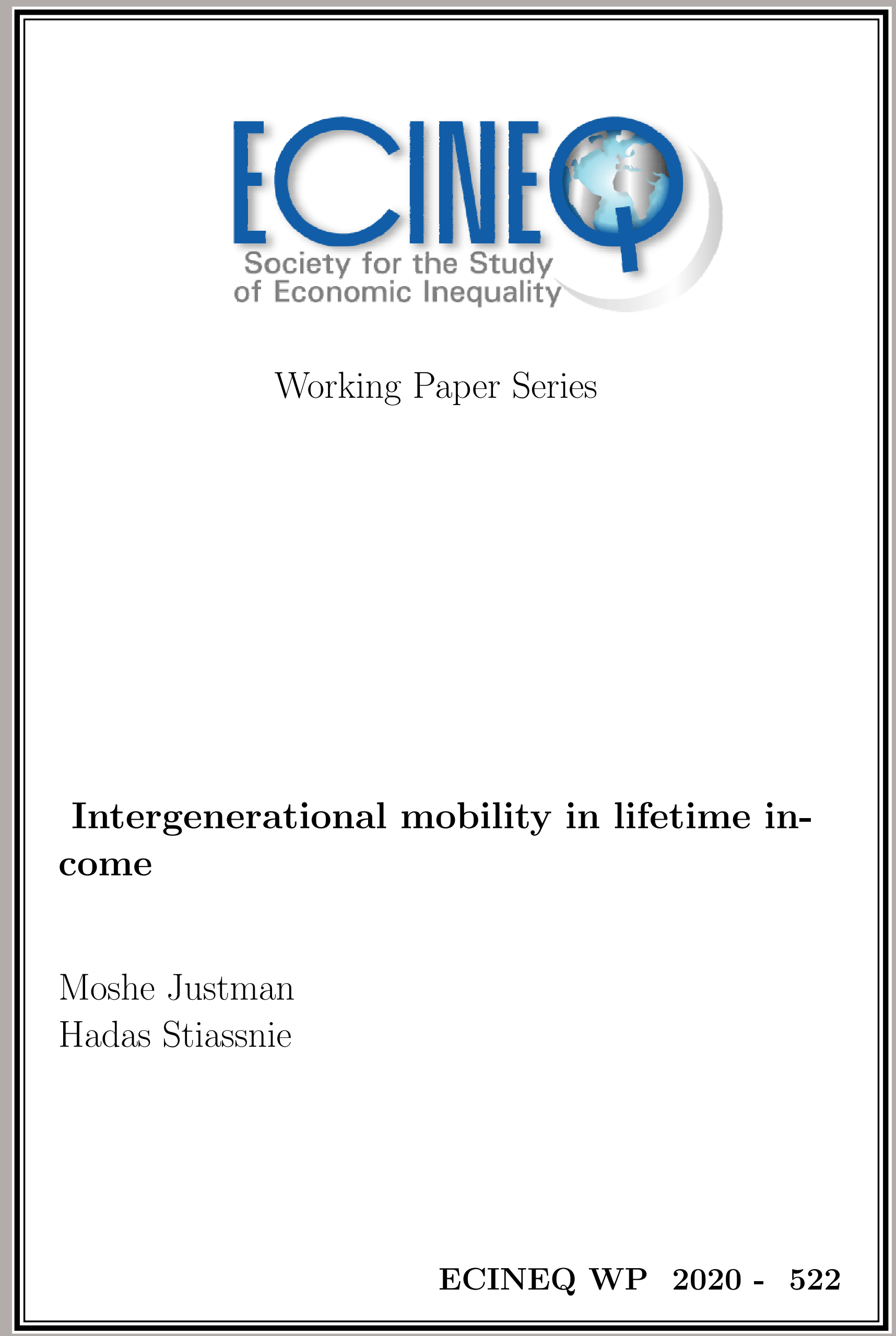




\title{
Intergenerational mobility in lifetime income
}

\author{
Moshe Justman \\ Ben Gurion University \\ Hadas Stiassnie \\ Ben Gurion University
}

\begin{abstract}
The two-stage approach to estimating intergenerational income mobility from panel data, proposed here, reduces age-related attenuation error and measurement error. The first stage estimates parents' and children's lifetime family income from linked longitudinal; the second stage uses these estimates to derive measures of absolute, relative and rank mobility. Applying this to United States PSID data, for sons born between 1952 and 1981 and their fathers, we find multiple indications of a decline in intergenerational mobility. This approach is robust to the addition of new data, and can be applied to improve the accuracy of mobility estimates derived from snapshot data.
\end{abstract}

Keywords: Intergenerational income mobility, lifetime income, PSID, absolute mobility, relative mobility, rank mobility.

JEL Classification: J62. 


\section{Intergenerational mobility in lifetime income}

\section{Introduction}

Intergenerational income mobility routinely focuses on links between annual income in a cohort of sons or daughters and their parents' average income as they were growing up, using these income observations as convenient proxies for lifetime income. However, these estimates are highly sensitive even to seemingly slight variations in research design. As Nybom and Stuhler $(2016,2017)$ have recently shown from Swedish administrative data-building on the earlier work of Haider and Solon (2006), Grawe (2006) and Hertz (2007)—findings typically based on annual snapshots of children's income when children are around 30 years old are sensitive to substantial attenuation error that exaggerates the extent of intergenerational mobility. ${ }^{1}$ The shape of age-income profiles varies with education and occupation, and there is more information in later income. Moreover, such snapshot measures of children's and parents' incomes are subject to significant measurement error, which introduces further bias. Measurement error in parental income introduces a downward bias in estimates of the intergenerational elasticity of income (IGE); measurement error in either parents' or children's income biases the Pearson correlation coefficient downward. Averaging income over several years reduces this bias (Solon, 1992), but the number of observations needed to remove all measurement error is generally larger than these studies have available (Mazumder, 2005).

We offer here a two-stage approach able to address these issues when long series of administrative data are not available. In particular, it yields reliable estimates of the intergenerational mobility of more recent cohorts, from income histories that are necessarily incomplete. Using linked, parent-child longitudinal data, the first stage estimates parents' and

\footnotetext{
${ }^{1}$ The show that mobility is underestimated when children's income is observed at age 50 .
} 
children's average lifetime income, exploiting all available data on income, education, race and marital status, to construct a set of shared age-income profiles, and predict individual annual income at age 40 . This serves as our estimate of average lifetime income. ${ }^{2}$ This avoids attenuation bias from variation in the age at which income is observed. Moreover, by making full use of the extensive income histories available for many individuals, and of the background variables available for all, it increases the accuracy of our income proxies for all individuals, including those observed only earlier or later in their work life, or with fewer income observations. In the second stage, we use these lifetime income estimates to construct a variety of mobility measures, which we average over ten-year cohort groups. Averaging over multiple cohorts reduces the ambiguity of relating cohort-based mobility measures to calendar time, as contemporary cohorts may experience different degrees of intergenerational mobility. ${ }^{3}$

To demonstrate this approach we apply it to linked longitudinal data from the United States Panel Study of Income Dynamics (PSID), available to 2016, estimating intergenerational mobility in lifetime family income between sons born between 1952 and 1981, and their

\footnotetext{
${ }^{2}$ This approach builds directly on Justman and Krush (2013). It extends Hertz (2007) and Lee and Solon $(2006,2009)$, which simultaneously estimated the IGE and the shape of ageeducation adjustments of income, where we estimate the two separately. We expand on this choice below.

${ }^{3}$ Of course, some ambiguity remains. Keeping the range of ages in each cohort-group constant over time, a wider range of ages would be more representative of a calendar year, but leave less scope for tracking mobility over time. Estimates for six-year and twelve-year cohortgroups produced very similar results.
} 
fathers. ${ }^{4}$ After deriving our proxy for average lifetime income - predicted income at age 40 we show that it exhibits a closer fit to actual average lifetime income for individuals observed in their prime earning years and with at least ten income observations, than commonly used snapshot proxies for lifetime income. We then use these income proxies to derive a range of specific time-variant measures of absolute, relative and positional intergenerational mobility. ${ }^{5}$ In each case, we average mobility over ten-year cohort groups, deriving estimates of all measures for our three disjoint groups, 1952-61, 1962-71 and 1972-81; and estimating some for a rolling sequence of 21 overlapping groups. If each cohort-group is nominally identified with the year in which sons are aged 30-39 - an arbitrary but reasonable association - this traces mobility from 1991 to 2011.

Anticipating our results, we note that a small majority of sons in our sample, about $57 \%$, experienced absolute upward mobility, with lifetime family incomes greater that their fathers'. Intergenerational income growth was substantially progressive throughout: where fathers' income in the highest quartile was more than three times greater than fathers' income in the lowest quartile, in all three cohort-groups, the mean income of sons of fathers in the highest quartile was less than twice the mean income of sons of fathers in the lowest quartile. We estimate the intergenerational elasticity of family income, for recent cohorts, at about 0.55 , consistent with the higher values advocated by Mazumder $(2016,2018)$ and Mitnik et al. (2017), and find multiple indications that absolute and relative intergenerational income

${ }^{4}$ The PSID, with its longitudinal structure and long history is uniquely suited to our approach. We limit our attention to sons born between 1952 and 1981 to maintain data quality.

${ }^{5}$ See Fields and Ok (1996), Fields (2006) and Jännti and Jenkins (2015), among others, on the multiple dimensions of intergenerational mobility. Our approach could similarly be applied to intergenerational mobility in labor income, between mothers and daughters; and so on. 
mobility have declined moderately over this period. With regard to positional mobility, interquartile transitional matrices reveal that the ends of the distribution - the highest and lowest quartiles - are "stickier" than the middle, as earlier studies have found. ${ }^{6}$ Throughout the period studied, the conditional probability of a son born into the highest income quartile remaining in the highest quartile, or of a son born onto the lowest quartile remaining in the lowest quartile ranges from $40 \%$ to $52 \%$, where corresponding probabilities for the middle quartiles are much lower. Rank-rank correlations have remained remarkably stable in the three middle quintiles of fathers' income distribution, with a slope of about 0.48 for all three cohort-groups, but changes at the top and bottom quintiles induced a slight decline in average positional mobility estimated over the full range of incomes. Finally, we show retrospectively that our time series are robust to the addition of new waves of PSID data, and to $50 \%$ sampling of individuals in the first-stage estimation of our lifetime income proxy.

We prefer our two-stage approach to simultaneously estimating age-education income adjustments and mobility measures, as Lee and Solon $(2006,2009)$ and Hertz (2007) did for the IGE, for two main reasons. First, it allows us to estimate the lifetime income parameters on a larger set of individuals, most of whom are not part of matched father-son pairs, while maintaining more stringent data requirements. This helps guard against overfitting the shape of the lifetime income function to the population of father-son pairs. Furthermore, as we use our income estimates to derive multiple measures of mobility, estimating lifetime income simultaneously with one of these measures, say the IGE, would favor one dimension of mobility over others. However, simultaneous estimation offers an important advantage: it allows a straightforward test of hypotheses on changes in mobility over time. For this purpose, we also present an alternative approach, estimating only fathers' lifetime incomes in the first

${ }^{6}$ This is not surprising, as the highest and lowest quartiles can only move in one direction. 
stage, and then incorporating these estimates in a simultaneous estimation of sons' lifetime incomes and cohort specific IGEs. This yields IGE estimates that are similar to our two-stage estimates, with the decline in mobility between the oldest and youngest ten-year cohort groups significant for a $p$-value of .06.

Finally, we note that the first stage of our analysis can be applied to improve the accuracy of intergenerational rank correlations (IRCs) estimated from "snapshot" single-year measures of income. This is relevant for analyses of large administrative datasets constrained by short income histories. We show, using our PSID data, that IRC trends estimated from snapshot data are only weakly correlated with trends derived from lifetime income estimates that draw on longer income histories. We then show how our first-stage results can be used to adjust these snapshot income measures, when background data on education, race and marital status are available, to estimate IRC trends that are closer in level and more closely correlated over time with estimated IRC trends based on lifetime incomes.

The structure of the paper is as follows. Section 2 describes our first-stage method and estimates average lifetime family income for fathers and sons. Section 3 uses these estimates to derive specific mobility measures and considers their variation over time. Section 4 analyzes the sensitivity of our findings to the addition of new waves of data and to sampling individuals in the first stage. Section 5 shows how our first-stage results can be used to refine snapshotbased estimates of intergenerational income mobility. Section 6 concludes.

\section{First stage analysis: estimating lifetime income}

The first stage of our two-stage approach derives proxies for lifetime family income by estimating the following Mincer-type equation over all males in our data set born between 1918 and 1981 with at least 3 non-zero income observations. 
(1) $y_{i j}=\alpha_{0 i} D_{i}+\alpha_{1} a g e_{i j}+\alpha_{2} a g e_{i j}^{2}+\alpha_{3} \boldsymbol{e d u c}_{\boldsymbol{i}} \cdot \operatorname{age}_{i j}+\alpha_{4} \boldsymbol{e d u c}_{\boldsymbol{i}} \cdot \operatorname{age}_{i j}^{2}+\alpha_{5}$ marstat $_{\boldsymbol{i}} \cdot \operatorname{ag}_{i j}$ $+\alpha_{6}$ marstat $_{\boldsymbol{i}} \cdot \operatorname{age}_{i j}^{2}+\alpha_{7} \boldsymbol{r a c e}_{\boldsymbol{i}} \cdot \operatorname{age}_{i j}+\alpha_{8} \boldsymbol{r a c e}_{\boldsymbol{i}} \cdot a g e_{i j}^{2}+\varepsilon_{i j}$

where $y_{i j}$ stands for $i$ 's individual's family income in year $j ; D_{i}$ is an individual fixed effect; $a g e_{i j}$ is individual $i$ 's age in year $j$; $\boldsymbol{e d u c}_{\boldsymbol{i}}, \boldsymbol{m a r s a t}_{\boldsymbol{i j}}$ and $\boldsymbol{r a c e}_{\boldsymbol{i}}$ are sets of dummy variables representing individual $i$ 's years of schooling, marital status at year $j$ and race; $\varepsilon_{i j}$ is an i.i.d. error term; and $\alpha_{0 i}, \alpha_{1} \ldots \alpha_{8}$ are the regression coefficients. This produces an age-income profile for each combination of education level, race and time pattern of marital status, and individual fixed effects, $D_{i}$. If $A g e_{i t}$ is entered as age in year $t$ minus 40, then $D_{i}$ is predicted income at age 40 . This is our proxy for average lifetime income. ${ }^{7}$ It is not actual income at age 40, even when we have it, but a prediction based on all income observations, education, race and marital status, with information on other individuals informing the coefficient estimates that shape the common age-income profiles.

Our data source is the Panel Study of Income Dynamics (PSID), from its inception in 1967 up to and including its latest wave, 2016, with data collected annually until 1996 and biannually thereafter. The PSID comprises two samples: a representative national sample drawn from the Survey Research Center (SRC), and a sample of low-income families, the Survey of Economic Opportunities (SEO). To avoid an over-representation of low-income families, we follow Lee and Solon (2006, 2009), Hertz (2007) and others, and use only the SRC sample. We restrict our attention to families in which the father is the head of household, and adjust all

\footnotetext{
7 The choice of age 40 follows Haider and Solon (2006), and Nybom and Stuhler (2017). Predictions at age 45 yield very similar IGE estimates (Appendix Figure A1); predictions at age 35 yield substantially lower values.
} 
income data to 2010 prices using the Consumer Price Index. ${ }^{8}$

Our base population comprises the 12,652 males in the SRC born between 1918 and 1981 with reported race and years of schooling. From these we extract 7,510 males with at least three positive income observations between the ages of 25 and 64, and use this, our "male sample", to estimate individuals' lifetime family income using equation (1). Appendix Table A1 presents estimation results and Appendix Figure A2 shows two age-income profiles derived from our first-stage estimation with individual fixed effects chosen to illustrate a rank reversal in income between the ages of 30 and 40 . We pool all observations in one estimation. Allowing age-income profiles to vary—by dividing the sample into similarly sized cohort groups and estimating income within each group (as in Justman and Krush, 2013)_yields similar results for the IGE, as Appendix Figure A3 shows. However, variances are greater for younger cohorts for which there is an insufficient basis for estimating age-income profiles in later years.

We then compare three income proxies to actual average lifetime income between age 30 and 55 for a subset of our male sample with higher data-quality: all 2,597 males born between 1937 and 1966 — and thus observed in their prime earning years — and with at least ten annual income observations ( 21 per person on average). The three income proxies we compare to actual averages are: predicted family income at age 40, which we compare to the actual average income for the entire sample of 2,597; average family income between the ages 29-31,

\footnotetext{
${ }^{8}$ Family income includes the taxable income (labor income, and income from assets, including rental, interest and dividend income) of all earners in the family unit, and the transfer income of all family members. To maintain comparability to previous studies we top-coded annual incomes over $\$ 150,000$ (at 1967 prices), and bottom-coded incomes below $\$ 150$ (at 1967 prices). This has no effect on our findings. Our approach is less sensitive to extreme values than single-stage estimates.
} 
for a subset of males with at least one income observation in that age range; and father's average family income when sons were aged 13-17, for fathers with 3 or more income observations in those years. ${ }^{9}$ The correlations presented in Table 1 , and scatter diagrams in Figure 1, highlight the greater accuracy we are able to achieve. The correlation between our income proxy and actual average lifetime income is 0.98 , where the correlation with average income at age 29-31 is much lower, 0.60, with corresponding rank correlations of 0.96 and 0.65. The correlation with fathers' average income when sons were aged 13-17, 0.91 , is substantially higher than at ages 29-31, but still lower than for predicted income at age 40, confirming that averaging parental income over several years substantially reduces measurement error but does not eliminate it (Solon, 1992; Mazumder, 2005). ${ }^{10}$

Table 1. Pearson correlation coefficients of average annual family income ages 30-55 with three lifetime income proxies, males born 1937-66, with 10 income observations or more

\begin{tabular}{|l|c|c|c|}
\hline & $N$ & Correlation & $\begin{array}{c}\text { Rank } \\
\text { correlation }\end{array}$ \\
\hline Predicted family income at age 40, all males in the range & 2,597 & 0.98 & 0.96 \\
\hline $\begin{array}{l}\text { Average family income, ages 29-31, subset of males with at } \\
\text { least one income observation in that age range }\end{array}$ & 1,344 & 0.60 & 0.65 \\
\hline $\begin{array}{l}\text { Fathers' average family income when sons were aged 13-17, } \\
\text { fathers with } 3 \text { or more income observations in those years }\end{array}$ & 1,408 & 0.91 & 0.95 \\
\hline
\end{tabular}

${ }^{9}$ A father of two sons can be included for one son but not another, or appear more than once with different incomes.

${ }^{10}$ Furthermore, dividing the fathers' sample into three equal parts by sons' birth cohort, we find correlations of fathers' average income when sons were aged 13-17 with their average income at ages $30-55$ of $0.92,0.87$ and 0.94 . The large drop in the middle years suggests a bias in estimated IGE trends using this measure. The corresponding correlations for our proxy, 0.95 , 0.97 and 0.98 , are higher, and vary less. 
Figure 1. Average actual family income, ages 30-55, plotted against: predicted income at age 40 for all PSID males born in 1937-66, with 10 income observations; average income at ages 29-31 for a subsample of males with an observation in that range; and average income when sons were aged 13-17, for fathers with 3 observations in those years. Income in 2010 dollars.
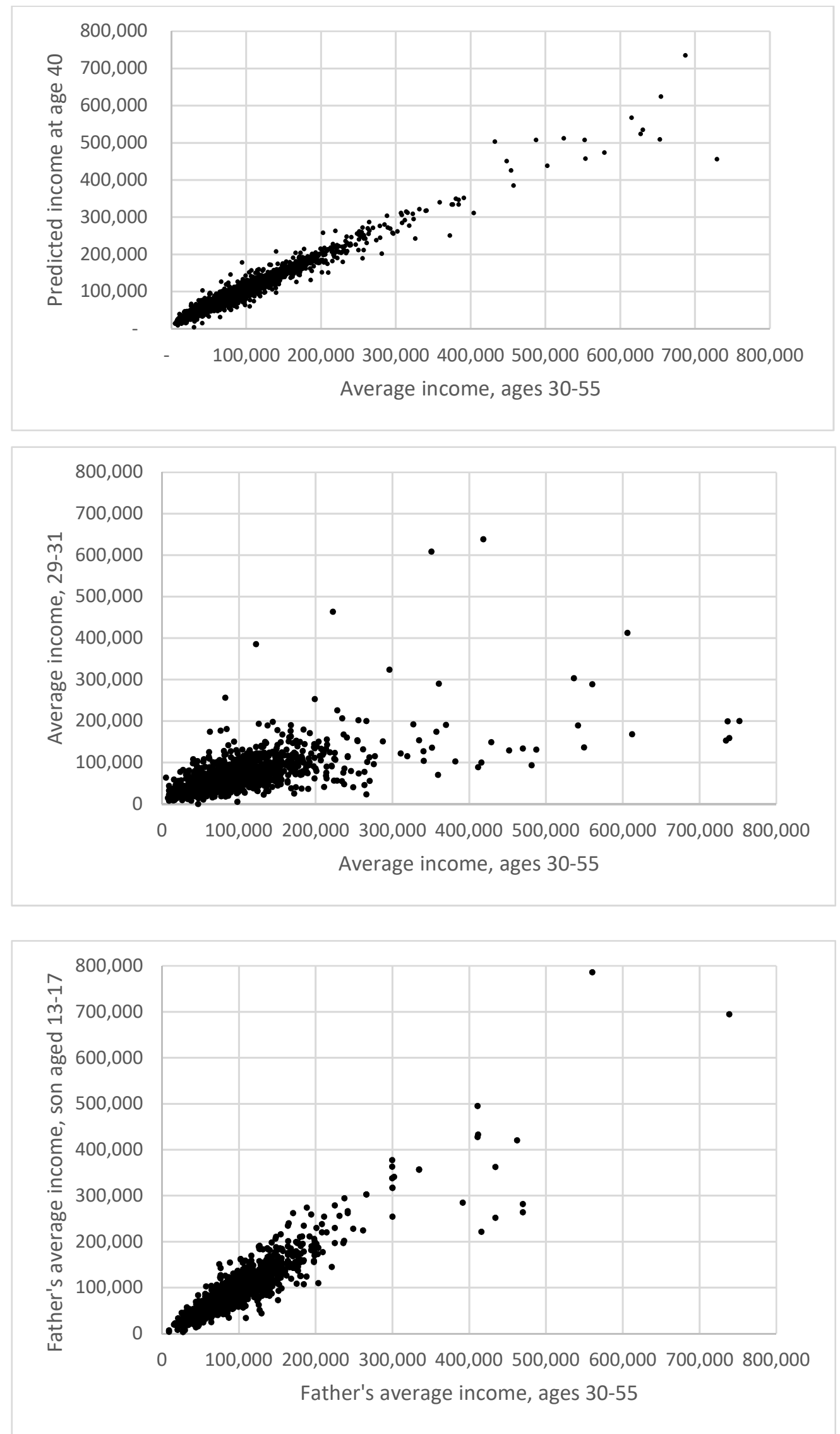
Next, we identify a sub-sample of our male sample, comprising 1,536 father-son pairs (1,316 fathers), of sons born between 1952 and 1981, for each of whom we have at least 3 positive income observations from age 29; and their fathers for whom we have at least 5 positive income observations between the age of 25 and 64. We refer to this as our "pairs sample". In the second stage, we use the predicted income of fathers and sons in the pairs sample to estimate multiple measures of intergenerational mobility in three disjoint ten-year cohort groups of sons, born in 1952-61, 1962-71 and 1972-81; and a subset of these measures for all 21 rolling ten-year cohort groups in this range. Table 2 presents basic descriptive statistics, means and standard deviations of our predicted average lifetime income and its logarithm, for sons and fathers in the three disjoint cohort groups. Appendix Tables A2 and A3 present these statistics for all 21 rolling ten-year cohort-groups.

Both fathers' and sons' mean years of schooling have risen over time, with sons' schooling rising less, so that the difference has narrowed. Father's mean age at son's birth fell by almost a year and a half between the oldest and youngest groups, a trend that has since dramatically reversed. This does not affect our lifetime income estimates, as we focus on predicted income at age 40 . The proportion of variance in income observations explained by the first-stage regression varies within a narrow range around a value of 0.60 . Cohort-group medians and means of predicted average lifetime family income have grown similarly for fathers and sons. Between the 1952-61 and 1972-81 cohorts, both medians grew by just over $7.5 \%$ and both means by about $5 \%$. However, where fathers' incomes initially fell then rose substantially, sons' incomes first rose and then hardly changed. Consequently, sons in the middle group, 1962-71, have lifetime incomes that exceed their fathers' by $13.2 \%$ at the median and $17.3 \%$ at the mean, where for the earlier and later groups, 1952-61 and 1962-71, the change is less than $9 \%$ at the median and less than $10 \%$ at the mean. Finally, we note that the slight 
drop in the standard deviation of fathers' log income over this period, combined with the increase for sons, contributed to the overall rise in the IGE, as we show in the following section.

Table 2. Descriptive statistics, fathers and sons in pairs sample, by sons' ten-year cohort group

\begin{tabular}{|c|c|c|c|c|c|c|c|c|c|c|}
\hline & \multirow{2}{*}{$\begin{array}{c}\text { Sons' } \\
\text { year of } \\
\text { birth }\end{array}$} & \multirow{2}{*}{$N$} & \multicolumn{2}{|c|}{$\begin{array}{c}\text { Mean number } \\
\text { of observations }\end{array}$} & \multicolumn{2}{|c|}{$\begin{array}{c}\text { Mean age of } \\
\text { observed } \\
\text { income }\end{array}$} & \multicolumn{2}{|c|}{$\begin{array}{c}\text { Mean years of } \\
\text { schooling }\end{array}$} & \multirow{2}{*}{$\begin{array}{c}\text { Father's } \\
\text { mean age } \\
\text { at son's } \\
\text { birth }\end{array}$} & \multicolumn{2}{|c|}{$\begin{array}{c}\text { Share of } \\
\text { variance } \\
\text { explained }\end{array}$} \\
\cline { 3 - 8 } & Fathers & Sons & Fathers & Sons & Fathers & Sons & & Sons \\
\hline $\begin{array}{c}1952- \\
61\end{array}$ & 477 & 23 & 20 & 50 & 37 & 12.5 & 14.0 & 28.6 & 0.618 & 0.552 \\
\hline $\begin{array}{c}1962- \\
71\end{array}$ & 468 & 29 & 12 & 44 & 35 & 13.2 & 14.0 & 27.7 & 0.576 & 0.607 \\
\hline $\begin{array}{c}1972- \\
81\end{array}$ & 591 & 25 & 7 & 41 & 32 & 13.8 & 14.4 & 27.2 & 0.632 & 0.646 \\
\hline
\end{tabular}

\begin{tabular}{|c|c|c|c|c|c|c|}
\hline \multirow{2}{*}{ Sons' year of birth } & \multicolumn{2}{|c|}{$\begin{array}{c}\text { Median predicted } \\
\text { average lifetime income }\end{array}$} & \multicolumn{2}{c|}{$\begin{array}{c}\text { Mean predicted } \\
\text { average lifetime income }\end{array}$} & \multicolumn{2}{c|}{$\begin{array}{c}\text { Standard deviation } \\
\text { of log income }\end{array}$} \\
\cline { 2 - 7 } & Fathers & Sons & Fathers & Sons & Fathers & Sons \\
\hline $1952-61$ & 82,616 & 90,001 & 92,127 & 101,251 & 0.476 & 0.503 \\
\hline $1962-71$ & 81,116 & 91,802 & 90,360 & 106,012 & 0.438 & 0.538 \\
\hline $1972-81$ & 89,108 & 96,848 & 97,105 & 106,291 & 0.469 & 0.535 \\
\hline $\begin{array}{c}\text { \% change, } 1952-61 \\
\text { to 1972-81 }\end{array}$ & $7.9 \%$ & $7.6 \%$ & $5.4 \%$ & $5.0 \%$ & $-1.5 \%$ & $6.4 \%$ \\
\hline
\end{tabular}

Note: $N$ is the number of father-son pairs in each cohort group; fathers can appear more than once.

Predicted average lifetime income is predicted annual income at age 40, in 2010 dollars, from a regression of all income observations on age and age squared, and their interaction with education, race and marital status, and individual fixed effects (equation 1). Explained variance is the proportion of variance in income observations explained by the first-stage regression, within each cohort-group, equal to 1 minus the sum of squared residuals from the first stage, for that cohort group, divided by the number of income observations for that group times their variance, separately for fathers and sons.

These inter-generational comparisons of lifetime family income do not have immediate counterparts in national statistics. National growth rates in median household income in the 
United States averaged 0.55\% annually in 1967-2016 (US Census Bureau, 2019a), and as fathers in our sample are, on average, 27 to 28 years older than their sons, the inter-generational differences we observe at the median are roughly comparable to national growth rates. This does not hold for mean household income, which grew $1 \%$ annually in that period, much more strongly than our sample means indicate. ${ }^{11}$ However, when we aggregate the individual family income observations in our pairs sample on an annual basis, to allow a more direct comparison, we find a close adherence to national trends. Comparing annual means and Gini coefficients in our pairs sample to national statistics for 1967-2016 (US Census Bureau, 2019a, 2019b) we find a correlation of 0.92 between our mean household income and the national mean, and 0.93 for the Gini coefficient (Appendix Figure A4 presents scatter diagrams). However, as our selection criteria create a more homogeneous and affluent sample than the general population, our mean incomes are higher and our Gini coefficients lower than national levels.

\section{Stage two: mobility measures}

In the second stage, we use our estimates of fathers' and sons' average lifetime income to derive specific measures of different dimensions of intergenerational mobility as they vary over time. We derive estimates of all measures for our three disjoint ten-year cohort-groups, 1952-61, 1962-71 and 1972-81; and estimates of some measures for a rolling sequence of 21 overlapping groups. Nominally identifying each cohort-group with the year in which sons were aged 30-39, the three disjoint groups are identified with the calendar years 1991, 2001 and

\footnotetext{
${ }^{11}$ The disparity at the mean, but not at the median, may be partly due to the rise in top incomes, not captured in the PSID sample.
} 
2011. Appendix Figure A5 presents scatter diagrams of fathers' and sons' estimated average lifetime family income for the three groups.

\subsection{Absolute upward mobility}

Throughout the period studied, a majority of sons experienced upward mobility in average lifetime income, compared to their fathers, as Table 3 shows numerically for our three disjoint groups and Figure 2 shows graphically for our rolling sequence of 21 overlapping ten-year cohort groups. The share of sons with higher lifetime income than their fathers peaked in the middle cohorts at a high of $61 \%$, and was lowest for the most recent cohort-group, $55 \%$. This is consistent with the son-to-father ratio of household income peaking for the middle, 1962-71 cohort group (Table 2, bottom panel). These findings are very similar to Chetty et al.'s (2017) estimates in both the level of absolute mobility and the downward trend, for our 1962-71 and 1972-81 cohort groups, however our estimate for the 1952-61 are somewhat lower than theirs. ${ }^{12}$ Our findings are also broadly in line with Acs et al.'s (2016) recent study of PSID data, which found that $63 \%$ of children born in 1963-68 had higher family income in their thirties than their parents at similar ages; and with Isaacs' (2007) finding, that $66 \%$ of children born in $1950-68$ had higher incomes in 1995-2002 than their parents in 1967-71. Lopoo and Deleire (2012) find a much higher share, $84 \%$, for these same cohorts. Halikias and Reeves (2016) identify various sources for these differences, among which is their measuring children's income at an age four

${ }^{12}$ As Chetty et al. (2017) note, they are able to observe the copula of parent-child earnings only from 1970. They assume a fixed copula for earlier cohorts and add (wide) upper and lower bounds to their baseline estimate. Our estimates are, of course, well within these bounds. Their estimates for yet earlier cohorts, outside our range, are higher. 
years older than their parents. In addition, the present study departs from these studies in its exclusive focus on fathers and sons, and in its access to more recent data. Moreover, our lifetime income measure factors in the future effect of the recent recession on predicted income probably, which may also contribute to lower levels of absolute upward intergenerational mobility.

Table 3. Fathers' and sons' lifetime family income, and \% sons with higher relative income than their fathers, by sons' birth cohort and father's income quartile.

\begin{tabular}{|c|c|c|c|c|c|c|}
\hline & $\begin{array}{c}\text { Fathers' } \\
\text { mean } \\
\text { income }\end{array}$ & $\begin{array}{c}\text { Sons' } \\
\text { mean } \\
\text { income }\end{array}$ & $\begin{array}{l}\text { Sons' mean } \\
\text { income growth } \\
\text { over fathers }\end{array}$ & $\begin{array}{c}\text { Cumulative } \\
\text { increase }\end{array}$ & $\begin{array}{c}\text { Share of sons } \\
\text { with income }> \\
\quad \text { fathers' }\end{array}$ & $\begin{array}{c}\text { Cumulative } \\
\text { share }\end{array}$ \\
\hline \multicolumn{7}{|l|}{$1952-61$} \\
\hline Lowest quartile & 46,156 & 71,200 & $54.3 \%$ & $54.3 \%$ & $78 \%$ & $78 \%$ \\
\hline $2^{\text {nd }}$ quartile & 72,429 & 97,090 & $34.0 \%$ & $41.9 \%$ & $69 \%$ & $74 \%$ \\
\hline $3^{\text {rd }}$ quartile & 94,827 & 109,873 & $15.9 \%$ & $30.3 \%$ & $56 \%$ & $68 \%$ \\
\hline Highest quartile & 154,573 & 126,628 & $-18.1 \%$ & $9.9 \%$ & $26 \%$ & $57 \%$ \\
\hline All & 91,996 & 101,198 & $9.9 \%$ & & $57 \%$ & \\
\hline $4^{\text {th }} Q / 1^{\text {st }} Q$ ratio & 3.35 & 1.78 & & & & \\
\hline \multicolumn{7}{|l|}{$1962-71$} \\
\hline Lowest quartile & 48,316 & 78,516 & $62.5 \%$ & $62.5 \%$ & $80 \%$ & $80 \%$ \\
\hline $2^{\text {nd }}$ quartile & 70,946 & 88,324 & $24.5 \%$ & $39.9 \%$ & $61 \%$ & $71 \%$ \\
\hline $3^{\text {rd }}$ quartile & 92,874 & 107,956 & $16.2 \%$ & $29.5 \%$ & $56 \%$ & $66 \%$ \\
\hline Highest quartile & 149,303 & 149,251 & $0.0 \%$ & $17.3 \%$ & $44 \%$ & $60 \%$ \\
\hline All & 90,360 & 106,012 & $17.3 \%$ & & $60 \%$ & \\
\hline $4^{\text {th }} Q / 1^{\text {st }} Q$ ratio & 3.09 & 1.90 & & & & \\
\hline \multicolumn{7}{|l|}{ 1972-81 } \\
\hline Lowest quartile & 49,561 & 74,400 & $50.1 \%$ & $50.1 \%$ & $72 \%$ & $72 \%$ \\
\hline $2^{\text {nd }}$ quartile & 76,783 & 96,647 & $25.9 \%$ & $35.4 \%$ & $61 \%$ & $67 \%$ \\
\hline $3^{r d}$ quartile & 100,381 & 116,784 & $16.3 \%$ & $27.0 \%$ & $57 \%$ & $63 \%$ \\
\hline Highest quartile & 162,136 & 137,545 & $-15.2 \%$ & $9.5 \%$ & $31 \%$ & $55 \%$ \\
\hline All & 96,997 & 106,239 & $9.5 \%$ & & $55 \%$ & \\
\hline $4^{\text {th }} Q / 1^{\text {st }} Q$ ratio & 3.27 & 1.85 & & & & \\
\hline
\end{tabular}


Figure 2. Share of sons aged 30-39 whose lifetime family income exceeded their fathers'

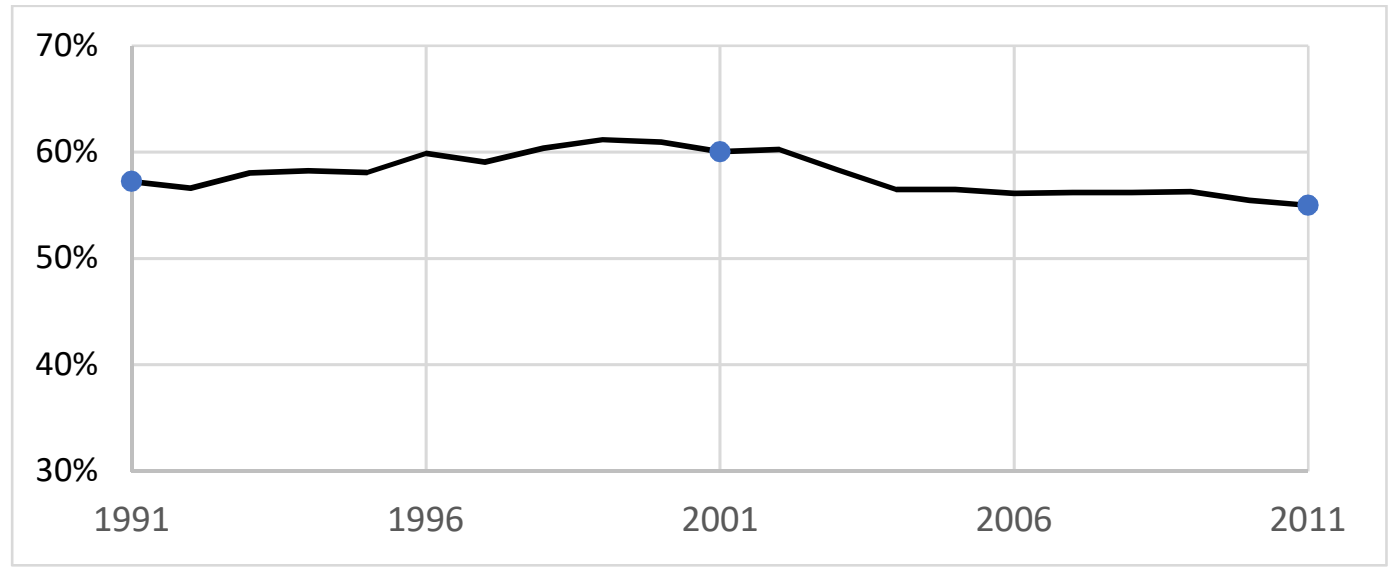

\subsection{The distributional incidence of intergenerational income growth}

A second salient feature of intergenerational income growth in the United States, which Table 3 highlights, is its progressive distributional incidence throughout the period studiedequalizing dynastic income and promoting economic opportunity. To illustrate this, we adapt measures developed to quantify corresponding dimensions of intra-generational mobility (Shorrocks, 1978; Fields, 2010; Bourguignon, 2010). Both the share of sons with lifetime income greater than their fathers, and the relative growth in sons' income over their fathers', fall steeply as father's income rises, within each of our three disjoint cohort-groups (Table 3, columns (3) and (5)). Consequently, where fathers' mean income in the highest quartile is more than three times greater than fathers' mean income in the lowest quartile, the mean income of sons of fathers in the highest quartile is less than twice the mean income of sons of fathers in the lowest quartile, in all three cohort-groups. This substantial drop reflects the progressive, equalizing distribution of intergenerational income growth throughout these years. To gauge changes in the degree of progressiveness of intergenerational income growth over time, we calculate the cumulative increase in sons' mean income over their fathers', in column (4) and in the share of sons' with higher income than their fathers, in column (6). We find that for both measures, the most recent cohort-group, 1972-81, is second-order dominated by both earlier 
cohort-groups, indicating that this effect has waned slightly, though the reduction in inequality is substantial throughout.

Further perspectives on this dimension of intergenerational mobility are provided by two closely related summary indices: Shorrocks' (1978) rigidity index and Fields (2010) index of mobility as an equalizer of longer-term incomes, applied here to intergenerational mobility, for each disjoint cohort-group (Table 4). Shorrocks' (1978) index compares the inequality of the sum of father's and son's lifetime family income to a weighted average of income inequality in each generation separately; Fields' index compares the inequality of the sum to inequality in fathers' incomes. We apply both indices to two measures of income inequality: Theil's index with $\alpha=0$, and the coefficient of variation. Both inequality measures confirm the progressiveness of intergenerational income growth we found in Table 3, showing reduced inequality for the sum of father and son incomes, compared to their separate inequality measures, for all three cohort-groups. However, the two indices provide different indications regarding the change in progressiveness over time. Shorrocks' index increases monotonically over time, indicating a moderate decline in progressiveness, while Fields' index is maximal for the middle cohort-group, with little difference between the oldest and youngest.

Table 4. Shorrocks' rigidity index and Fields' equalization index for two inequality measures

\begin{tabular}{cccccc}
\hline $\begin{array}{c}\text { Sons'birth } \\
\text { cohorts }\end{array}$ & $\begin{array}{c}\text { Father's } \\
\text { income }\end{array}$ & $\begin{array}{c}\text { Son's } \\
\text { income }\end{array}$ & $\begin{array}{c}\text { Sum of } \\
\text { incomes }\end{array}$ & $\begin{array}{c}\text { Shorrocks' } \\
\text { index }\end{array}$ & $\begin{array}{c}\text { Fields' } \\
\text { index }\end{array}$ \\
\hline Theil index $(\alpha=0)$ & & & & & \\
\hline $1952-61$ & 0.119 & 0.126 & 0.090 & 0.735 & 0.756 \\
$1962-71$ & 0.105 & 0.149 & 0.096 & 0.743 & 0.914 \\
$1972-81$ & 0.117 & 0.135 & 0.095 & 0.754 & 0.812 \\
\hline \multicolumn{2}{l}{ Coefficient of variation } & & & & \\
\hline 1952-61 & 0.591 & 0.560 & 0.462 & 0.804 & 0.782 \\
$1962-71$ & 0.565 & 0.625 & 0.492 & 0.824 & 0.871 \\
$1972-81$ & 0.601 & 0.536 & 0.469 & 0.828 & 0.780 \\
\hline
\end{tabular}




\subsection{Relative income mobility}

We find multiple indications of a moderate decline in intergenerational mobility in relative income between our oldest and youngest cohort-groups. The most direct indications are the increase, over time, in the correlation and rank correlation between fathers' and sons' lifetime family incomes (Table 5). In each case, the correlation for our youngest cohort-group is higher than for the two older cohort-groups, indicating a decline in intergenerational mobility. Another indicator that points in the same direction is the average change in income between father and sons, as a fraction of fathers' average income (Fields, 2006), which fell from $43.7 \%$ for the oldest cohort-group to $41.5 \%$ for the youngest.

Table 5. Father-son lifetime income correlations and rank correlations, by cohort-group

\begin{tabular}{cccc}
\hline Sons' birth cohorts & $N$ & Correlation & Rank correlation \\
\hline $1952-61$ & 477 & 0.29 & 0.45 \\
$1962-71$ & 468 & 0.35 & 0.45 \\
$1972-81$ & 591 & 0.37 & 0.51 \\
\hline
\end{tabular}

Table 6 offers further indication of a decline in relative mobility, presenting corresponding calculations to Table 3, for fathers' and sons' relative incomes. As all three cohort-groups experienced positive intergenerational income growth, the overall share of sons gaining ground in relation to their fathers is smaller than for absolute income, but the patterns are similar. In all three cohort-groups, growth in relative income is strongly progressive across fathers' income quartiles, the ratio of sons' relative income to their fathers' falling markedly with father's income; and the rightmost column of Table 6 shows that this dimension of progressiveness declines slightly over time. Cumulative intergenerational growth in relative income in the youngest cohort-groups is second-order dominated by the oldest cohort-group. 
Table 6. Fathers' and sons' lifetime family income in relation to their generational average, by sons' birth cohort and father's income quartile

\begin{tabular}{ccccc}
\hline & $\begin{array}{c}\text { Fathers' mean } \\
\text { relative income }\end{array}$ & $\begin{array}{c}\text { Sons'mean } \\
\text { relative income }\end{array}$ & $\begin{array}{c}\text { Sons'growth in } \\
\text { relative income } \\
\text { over fathers }\end{array}$ & $\begin{array}{c}\text { Cumulative } \\
\text { growth }\end{array}$ \\
\hline 1952-61 & & & & \\
\hline Lowest quartile & $50 \%$ & $70 \%$ & $40 \%$ & $40.4 \%$ \\
$2^{\text {nd }}$ quartile & $79 \%$ & $96 \%$ & $22 \%$ & $29.1 \%$ \\
$3^{\text {rd }}$ quartile & $103 \%$ & $109 \%$ & $5 \%$ & $18.6 \%$ \\
Highest quartile & $168 \%$ & $125 \%$ & $-26 \%$ & $0.0 \%$ \\
\hline 1962-71 & & & & \\
\hline Lowest quartile & $53 \%$ & $74 \%$ & $39 \%$ & $38.5 \%$ \\
$2^{\text {nd }}$ quartile & $79 \%$ & $83 \%$ & $6 \%$ & $19.2 \%$ \\
$3^{\text {rd }}$ quartile & $103 \%$ & $102 \%$ & $-1 \%$ & $10.4 \%$ \\
Highest quartile & $165 \%$ & $141 \%$ & $-15 \%$ & $0.0 \%$ \\
\hline 1972-81 & & & & \\
\hline Lowest quartile & $51 \%$ & $70 \%$ & $37 \%$ & $37.1 \%$ \\
$2^{\text {nd }}$ quartile & $79 \%$ & $91 \%$ & $15 \%$ & $23.7 \%$ \\
$3^{\text {rd }}$ quartile & $103 \%$ & $110 \%$ & $6 \%$ & $16.0 \%$ \\
Highest quartile & $167 \%$ & $129 \%$ & $-23 \%$ & $0.0 \%$ \\
\hline
\end{tabular}

Note: Father's relative income is father's income divided by fathers' average income within each cohort-group; and similarly, for sons.

The IGE is arguably the most widely used (inverse) measure of relative mobility, regressing the logarithm of sons' average lifetime family income, $y_{i}$, on the logarithm their fathers' income, $x_{i}$ :

(2) $\ln y_{i}=\alpha+\beta \ln x_{i}+\varepsilon_{i}$

The slope $\beta$ is our estimate of the IGE of family income, regressed here within each tenyear cohort group. Table 7 reports IGE estimates for our three disjoint cohort-groups, along with Pearson correlations in $\log ($ income $)$, a measure of goodness of fit of the regression equation; son-to-father ratios of the standard deviation of log income (reported separately in Table 2); and slopes from quintile regressions of the conditional median. The increase of the 
IGE, from 0.458 for the oldest cohort-group to 0.561 for the youngest, is another indication of the decline in relative mobility. Estimates for all 21 rolling ten-year cohort-groups, shown graphically in Figure 3 and numerically in Appendix Table A4, present a more nuanced pattern (calendar years refer to the year in which sons are aged 30-39): a modest increase in the first decade, followed by an accelerated rise from 2000 to 2004, and finally a leveling off.

Table 7. The intergenerational elasticity (IGE) of lifetime family income, correlations of log(income), ratio of standard deviations, and quintile regression slopes, by sons' cohorts

\begin{tabular}{ccccccc}
\hline $\begin{array}{c}\text { Sons'birth } \\
\text { cohorts }\end{array}$ & $N$ & $\begin{array}{c}\text { IGE } \\
\text { estimate }\end{array}$ & $\begin{array}{c}2^{\text {nd }} \text { stage } \\
\text { standard } \\
\text { error }\end{array}$ & $\begin{array}{c}\text { Father-son } \\
\text { correlation of } \\
\text { log income }\end{array}$ & $\begin{array}{c}\text { Son to father ratio } \\
\text { of std deviations } \\
\text { of log income }\end{array}$ & $\begin{array}{c}\text { Quintile } \\
\text { regression } \\
\text { slope }\end{array}$ \\
\hline $1952-61$ & 477 & 0.458 & 0.044 & 0.432 & 1.058 & 0.42 \\
$1962-71$ & 468 & 0.540 & 0.051 & 0.440 & 1.228 & 0.48 \\
$1972-81$ & 591 & 0.561 & 0.041 & 0.492 & 1.140 & 0.57 \\
\hline
\end{tabular}

Figure 3. Estimates of the intergenerational elasticity (IGE) of average lifetime family income, between sons aged 30-39 and their fathers, 1991-2011

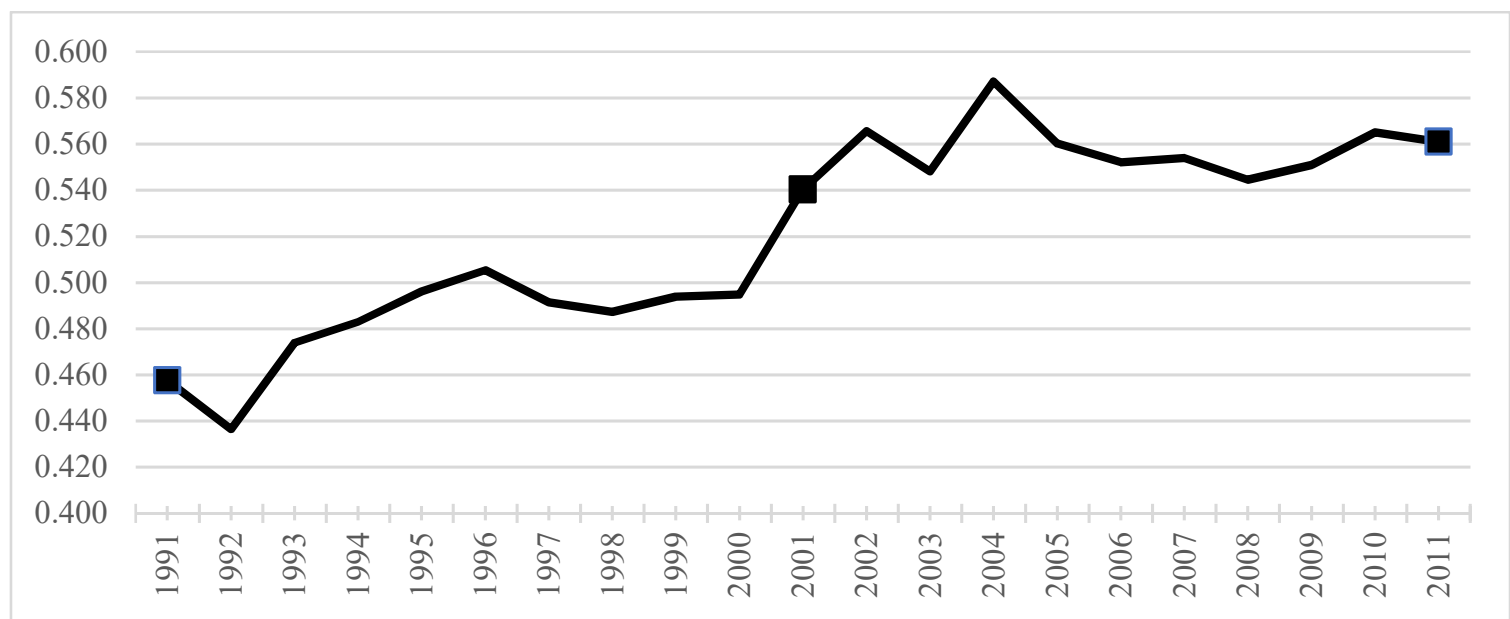

Note: Average lifetime family income estimated in a first stage from all income observations, allowing age-income profiles to vary by education, race and marital status (equation 1). Values for the three disjoint cohort groups, of sons born in 1952-61, 1962-71 and 1972-81, are marked. 
The change in the IGE from the first to the last cohort-group is twice the second-stage standard errors for the IGE. However, as our income proxies are themselves estimates, usual significance tests do not apply. To shed further light on the statistical significance of these differences we only estimated fathers' lifetime incomes in the first stage, and then simultaneously estimated sons' lifetime incomes and IGE slopes, specifically estimating:

$$
\begin{gathered}
\log \left(y_{i j}\right)=\alpha_{c}+\beta_{c} \cdot \log \left(\hat{x}_{i}\right)+\alpha_{1} a g e_{i j}+\alpha_{2} \text { age }_{i j}^{2}+\alpha_{3} \text { educ }_{\boldsymbol{i}} \cdot \text { age }_{i j}+\alpha_{4} \text { educ }_{\boldsymbol{i}} \cdot \text { age }_{i j}^{2} \\
+\alpha_{5} \text { marstat }_{i j} \cdot \text { age }_{i j}+\alpha_{6} \text { marstat }_{i j} \cdot \text { age }_{i j}^{2}+\alpha_{7} \text { race }_{\boldsymbol{i}} \cdot \text { age }_{i j} \\
\quad+\alpha_{8} \text { race }_{\boldsymbol{i}} \cdot \text { age }_{i j}^{2}+\varphi_{i}+\varepsilon_{i j}
\end{gathered}
$$

over all sons' income observations, where $\log \left(\hat{x}_{i}\right)$ is the logarithm of father's predicted income at age 40 from the first stage; and the constants and slope of father's income are allowed to vary across the three disjoint cohort-groups (other variables are as defined for equation 1). The results are presented in Table 8 . The IGE estimates are similar to those obtained from the twostage method for the oldest and youngest groups, but somewhat lower for the middle group. Testing the hypothesis that the IGE for the youngest group is higher than for the oldest group, we find that it is significantly higher for a $p$-level of $0.06 .^{13}$

\footnotetext{
${ }^{13}$ Without clustering, the $p$-value is much smaller, less than 0.0001 . We also estimated the logarithm of lifetime income directly from equation (1) and obtained very similar results. Raising $e$ to the power of these estimates, we found a correlation of 0.975 with predicted lifetime income from our principal estimation, over all 7,510 individuals in the male sample.
} 
Table 8. The intergenerational elasticity (IGE) of lifetime family income, estimated simultaneously with sons' lifetime income, by cohort group.

\begin{tabular}{ccccc}
\hline $\begin{array}{c}\text { Sons' birth } \\
\text { cohorts }\end{array}$ & $\begin{array}{c}\text { Number of } \\
\text { sons }\end{array}$ & $\begin{array}{c}\text { Number of income } \\
\text { observations }\end{array}$ & $\begin{array}{c}\text { IGE } \\
\text { estimates }\end{array}$ & Standard errors \\
\hline $1952-61$ & 477 & 9,643 & 0.442 & 0.048 \\
$1962-71$ & 468 & 5,795 & 0.472 & 0.061 \\
$1972-81$ & 591 & 4,058 & 0.550 & 0.051 \\
\hline
\end{tabular}

$N=19,496 . \quad R^{2}=0.252 \quad$ Standard errors clustered at the level of individual sons.

Representing the elasticity coefficient $\beta$ as a product of the Pearson correlation coefficient between the logarithm of sons' and father's incomes, $r$, and the ratio of the standard deviations of the logarithm of sons' and fathers' incomes, $\sigma_{s} / \sigma_{f}$ sheds further light on these trends.

(4) $\beta=r\left(\sigma_{s} / \sigma_{f}\right)$

As Figure 4 shows graphically for all 21 rolling cohort-groups (and Appendix Table A5 shows numerically), the initial increase in the intergenerational elasticity of income corresponds to a rise in the ratio of the standard deviations, mostly reflecting an initial decline in the dispersion of fathers' log-incomes and a slight increase among sons. The stronger increase in the middle years reflects a concomitant rise in both measures; and the stability of the IGE among recent cohorts is the net effect of a rise in the correlation of log-incomes offset by a fall in the ratio of standard deviations. 
Figure 4. The correlation between the logarithms of lifetime income of sons aged 3039, and their fathers, and the ratio of their standard deviations (sons' over fathers')

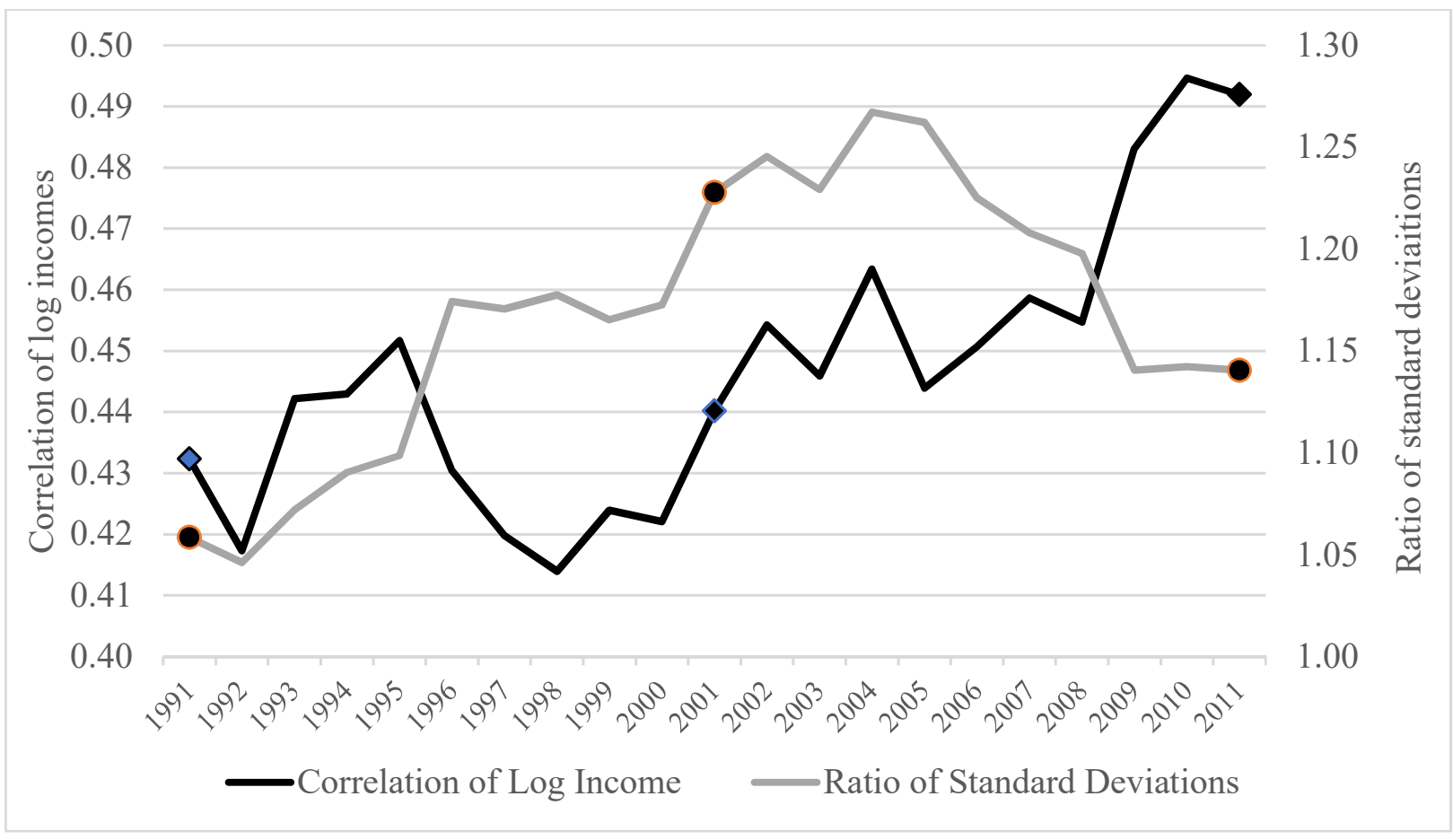

Note: Lifetime family income estimated in a first stage from all income observations, allowing the shape of life-cycle earnings to vary by education, race and marital status (see text for further details). The three disjoint cohort groups, 1952-61, 1962-71 and 1972-1981, are marked.

While our findings on absolute upward mobility and the distributional incidence of intergenerational income growth are generally in line with previous research, earlier PSIDbased studies of trends in the IGE, recently surveyed by Mazumder (2018), did not find rising trends. ${ }^{14}$ Thus Mayer and Lopoo's (2005) early study of sons born between 1949 and 1965 focused on their annual family income, looking singly at each cohort of about thirty sons, and obtained very volatile year-to-year estimates with no significant trend. Subsequent studies by Lee and Solon (2006, 2009) and Hertz (2007) of trends in intergenerational elasticities among sons born between 1952 and 1979, from data to 2000, also did not find a significant trend, again

${ }^{14}$ These are negative findings; none found a "precisely measured zero" trend. 
with wide variation year-to year. Their method is close to our simultaneous estimates. We attribute our finding a significant decline in mobility, where they found no significant trend, to having eight more waves of data (their youngest cohort is observed only to age 21); estimating the IGE within ten-year cohort-groups; and using more accurate first-stage estimates of fathers' incomes as right-hand variables.

Closest to the present analysis, Durlauf et al. (2017) use income observations to 2010 to estimate intergenerational elasticities for sons born between 1952 and 1975, and aggregating father-son pairs in successive ten-year cohort groups. They average out sons' income between the ages of 25 and 34; and average out fathers' income when their sons were aged 13 to 17. Their IGE estimates show an initial downward trend, levelling off in later years, and ranging from an early high of 0.47 to a more recent low of 0.34 . These latter IGE estimates are substantially lower than the IGE levels advocated by Mazumder (2016) and Mitnik et al. (2018). ${ }^{15}$ This leads us to attribute the difference between our results and theirs to our different treatment of parental income, and indeed, when we replicate their method on our sample (and find similar estimates) the difference largely disappears when we substitute our estimate of fathers' lifetime income for their five-year average (Appendix Figure A6).

Aaronson and Mazumder's (2008) study of trends in intergenerational mobility from census data applies a different methodology. Using decennial US census data from 1940 to 2000, they also find a decline in intergenerational mobility. However, these findings are

15 They argue for values certainly greater than 0.5 and possibly as high as 0.6 . Both use large administrative data sets to minimize measurement error in parental income and address lifecycle bias. See also our own findings, reported in Figure 1, Table 1 and note 10, above; and Nybom and Stuhler's $(2016,2017)$ analysis of Swedish data discussed in the introduction. 
difficult to compare to ours because of the different time-frames and differences in methodology. As their census data is not linked across generations, they use children's stateof-birth as an instrument for parental income, implicitly assuming a stable relation between parental income and state of residence.

\subsection{Positional mobility}

Earlier work on intergenerational positional mobility-between social classes, occupations, years of schooling or income levels - made extensive use of inter-quantile mobility matrices, which allow a more nuanced picture of mobility than summary measures. Table 9 presents inter-quartile father-son mobility matrices in lifetime family income for our three disjoint cohort groups (each row summing to 0.25 , subject to rounding).

Table 9. Intergenerational rank mobility in lifetime family income, by quartiles

\begin{tabular}{llllll}
\hline \multirow{4}{*}{ 1952-61 } & & \multicolumn{4}{c}{ Sons } \\
\cline { 3 - 6 } Fathers & $1^{\text {st }} Q$ & $2^{\text {nd }} Q$ & $3^{\text {rd }} Q$ & $4^{\text {th }} Q$ \\
\cline { 2 - 6 } & $1^{\text {st }} Q$ & 0.13 & 0.06 & 0.05 & 0.02 \\
\cline { 2 - 6 } & $2^{\text {nd }} Q$ & 0.06 & 0.09 & 0.05 & 0.05 \\
\cline { 2 - 6 } & $3^{\text {rd }} Q$ & 0.04 & 0.06 & 0.07 & 0.08 \\
\cline { 2 - 6 } & $4^{\text {th }} Q$ & 0.02 & 0.04 & 0.08 & 0.10 \\
\hline
\end{tabular}

$1962-71$

\begin{tabular}{llllll}
\hline \multirow{5}{*}{ Fathers } & $1^{\text {st }} Q$ & 0.10 & 0.09 & 0.03 & 0.03 \\
\cline { 2 - 6 } & $2^{\text {nd }} Q$ & 0.08 & 0.07 & 0.07 & 0.03 \\
\cline { 2 - 6 } & $3^{\text {rd }} Q$ & 0.05 & 0.05 & 0.09 & 0.06 \\
\cline { 2 - 6 } & $4^{\text {th }} Q$ & 0.02 & 0.04 & 0.06 & 0.13 \\
\hline
\end{tabular}

1972-81

\begin{tabular}{llllll}
\hline \multirow{5}{*}{ Fathers } & $1^{\text {st }} Q$ & 0.13 & 0.06 & 0.04 & 0.02 \\
\cline { 2 - 6 } & $2^{\text {nd }} Q$ & 0.07 & 0.08 & 0.06 & 0.04 \\
\cline { 2 - 6 } & $3^{\text {rd }} Q$ & 0.04 & 0.07 & 0.07 & 0.08 \\
\cline { 2 - 6 } & $4^{\text {th }} Q$ & 0.01 & 0.04 & 0.09 & 0.11 \\
\hline
\end{tabular}

The oldest and youngest cohort groups have very similar mobility matrices, while the 1962-71 cohort group exhibits a different pattern. However, in all three, the ends of the 
distribution — the highest and lowest quartiles_-are "stickier" than the middle, as earlier studies have found (Isaacs, 2007; Bengali and Daly, 2012; Acs et al., 2016). The conditional probability of the son of a father in the lowest quartile remaining in the lowest quartile is $50 \%$ for the 1952-61 cohort-group, 40\% for the 1962-71 group and 52\% for the 1972-81 group, while the corresponding probabilities for a son born into the highest quartile remaining in the highest quartile are $40 \%, 52 \%$ and $44 \%$. If sons' income ranks were independent of their fathers', these probabilities would all equal 0.25 . This indicates the limits of progressiveness of income growth: there remains considerable origin dependence for sons born into the highest and lowest quartiles while sons born to fathers in the middle two quartiles face much more even conditional distributions. Moreover, these numbers indicate that both the top and bottom quartiles are slightly "stickier" for the youngest cohort-group than for the oldest, indicating a modest decline in positional mobility. This finds further support in another summary measure of positional mobility, the weighted sum of interquartile change, each matrix entry weighted by its distance from the diagonal. It equals $0.84,0.84$ and 0.87 from the oldest to the youngest cohort-group. However, a third summary measure, one minus the sum of diagonal entries (the trace), shows no change: $0.61,0.62$ and 0.61 for the three cohort-groups.

The recent, influential work of Chetty and associates (2014a, 2014b) has drawn increased attention to the intergenerational income rank correlation (IRC) of income, or equivalently the rank-rank regression slope, as a summary measure of intergenerational positional mobility, which they use to compare mobility across regions and over time. We apply this measure to our lifetime family income estimates, calculating IRCs within all 21 rolling ten-year cohort groups. These are presented graphically in Figure 5, and numerically in Appendix Table A4. The IRC values for our disjoint cohort groups $-0.453,0.452$ and 0.506 
from oldest to youngest—indicate an overall decline in rank mobility ${ }^{16}$ The graph in Figure 5 presents a more detailed picture. Identifying each cohort-group with the year its members are aged 30-39, we find little change in the first decade, from 1991 to 2000, followed by a gradual increase, which accelerates after 2008. This latter decline in positional mobility may be an effect of the financial crisis of 2008 .

Figure 5. Estimates of the rank correlation of average lifetime family income, between sons aged 30-re 39 and their fathers, 1991-2011

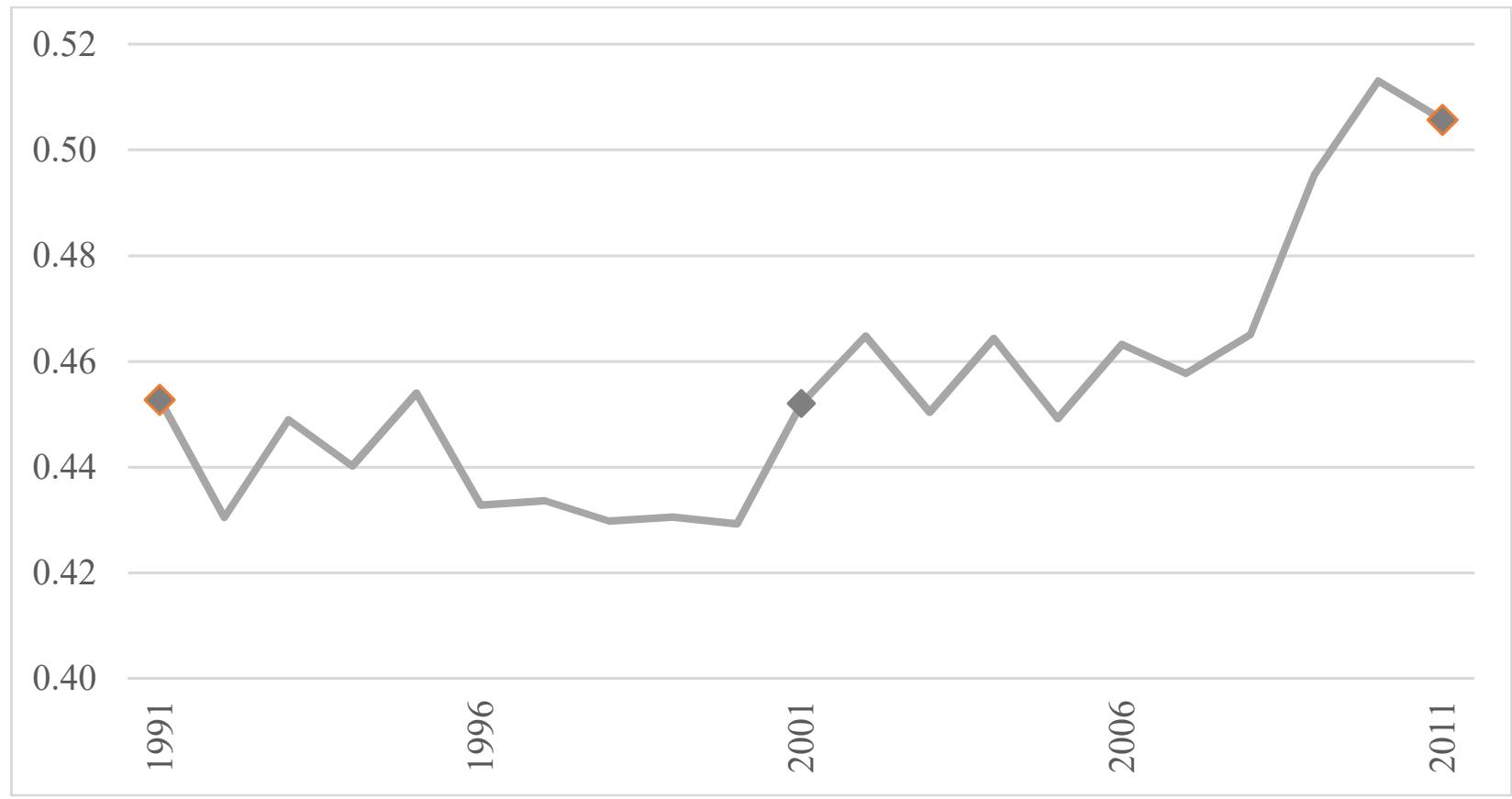

Note: Average lifetime family income estimated in a first stage from all income observations, allowing age-income profiles to vary by education, race and marital status (see text for further details). The three disjoint cohort groups, of sons born in 1952-61, 1962-71 and 1972-81, are marked individually.

${ }^{16}$ OLS standard errors from a rank-rank regression range between .036 and .042. However, as the income proxies are themselves estimates, usual significance tests do not apply. We discuss robustness of our estimates to first-stage sampling and the addition of new data in Section 4 . We find a correlation of 0.65 between the IGE and the IRC across our 21 cohort groups. 
These findings are not directly comparable to Chetty et al.'s (2014a) estimates of singlecohort intergenerational rank correlations for sons born between 1971 and 1986, at age 30, using tax records on very large samples, which found no trend. ${ }^{17}$ However, they also report rank correlations in annual income for three four-year cohort groups, 1971-74, 1975-78, and 1979-82, finding values of 0.299, 0.291 and 0.313 (Chetty et al., 2014a, Figure 1). Estimating corresponding intergenerational rank correlations in our measure of lifetime family income for the three cohort groups 1971-74, 1975-78 and 1979-81, we find a similar dynamic pattern: little change between the first two cohort-groups, where we find values of 0.450 and 0.453 , followed by an increase to 0.619 for our more recent group. We attribute the much lower elasticity values they obtain to their use of snapshot measures of income at age 30, which bias their estimates downward, as argued carefully by Mazumder (2016) and Mitnik et al. (2018), and indicated by the IRC estimates we obtain from similar snapshot income data, in Section 5 (Figure 9), below.

We conclude this section with a local quadratic approximation of our rank-rank regression for each of the three cohort-groups, using Stata's LOWESS procedure, to allow for non-linearities (Figure 6). We find such non-linearities at both ends of the distribution, with each cohort-group following a different pattern. However, in the middle of the distribution, the intergenerational rank-rank link is linear and nearly identical for all three groups, with a common slope of 0.48 , equal to the slope from the quantile regression for the $1962-71$ cohortgroup (Table 7). ${ }^{18}$ This indicates that the higher rank correlation and quintile regression slope

\footnotetext{
${ }^{17}$ For later cohorts, born between 1986 and 1993, they measure intergenerational mobility with regard to college enrolment at age 19 . This is entirely outside our time frame (and estimates intergenerational educational mobility rather than income mobility).
}

${ }^{18}$ Localized IGE graphs for the three cohort-groups do not coincide in the same way. 
we found for the youngest cohort-group, compared to the two older groups, is driven by reduced mobility at the ends of the distribution. This is consistent with our analysis of interquartile mobility matrices, above.

Figure 6. Quadratic local approximation of rank-rank regressions, by sons' cohort-group, using Stata's LOWESS procedure

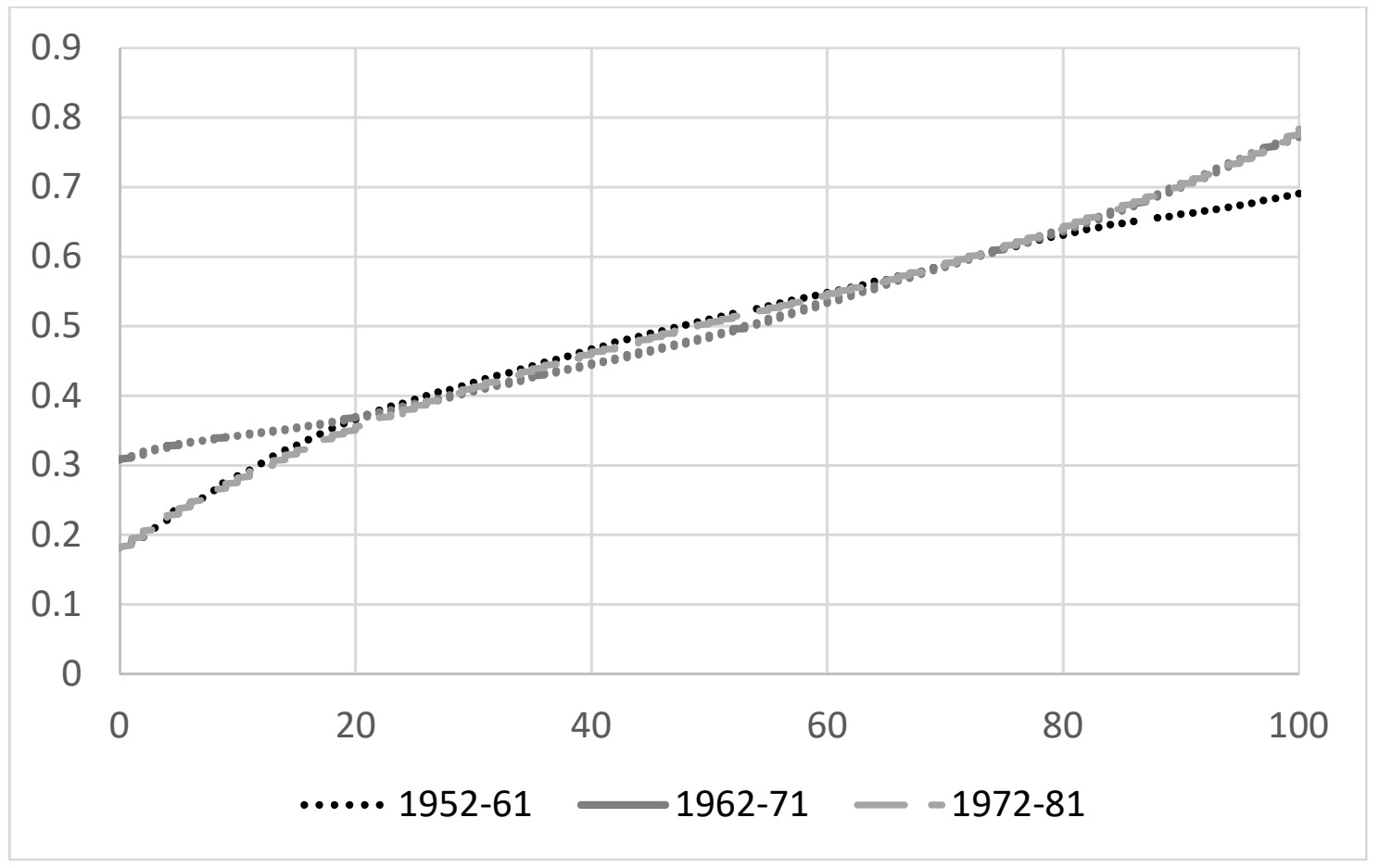

\section{Robustness}

A key advantage of our two-stage method is its efficient use of data in projecting income estimates into the future to obtain more reliable estimates of lifetime income. To illustrate this, we demonstrate the robustness of our estimates to the addition of new waves of data, and to $50 \%$ sampling of individuals in the first stage. To demonstrate robustness of our findings to the addition of new waves of data, we estimate IGE and IRC regressions using only data available in previous years, and compare the results to estimates based on all currently available data. Specifically, we first restrict the data to the 2006 wave and earlier, and implement our twostage method to yield IGE and IRC estimates for ten-year cohort groups of males aged 30 or 
over in 2001 . We then repeat this process using data up to 2008 for males aged 30 or over in 2003, and so on for each wave, up to the latest, which uses all data to 2016 for sons aged 30 or over in 2011. Figure 7 presents the results for the IGE and IRC.

Figure 7. Intergenerational elasticities (IGE; top panel) rank correlations (IRC; bottom panel) of lifetime family income, between sons aged 30-39 and their fathers, using all PSID waves to 2016, 2014, 2012, 2010, 2008 and 2006; 1991-2011

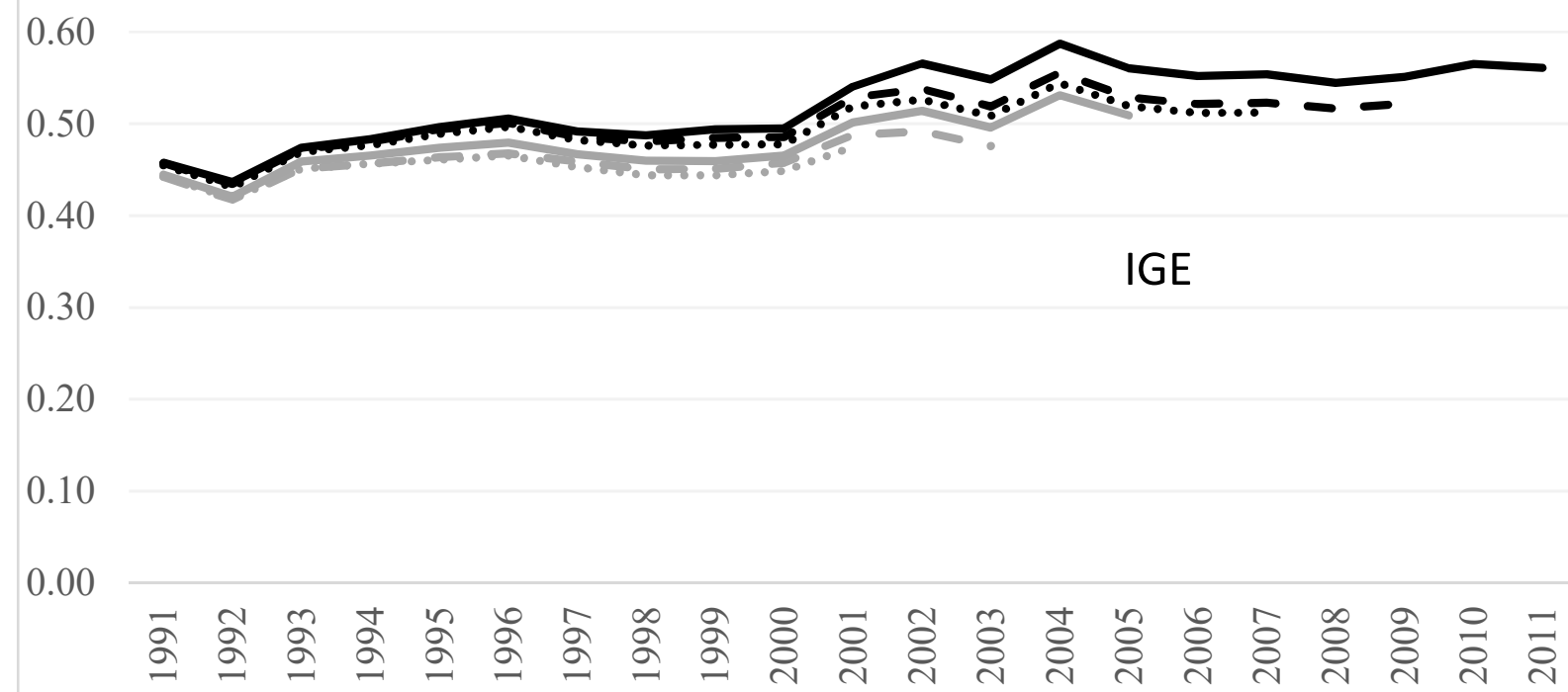

0.60

0.50

0.40

0.30

IRC

0.20

0.10

0.00

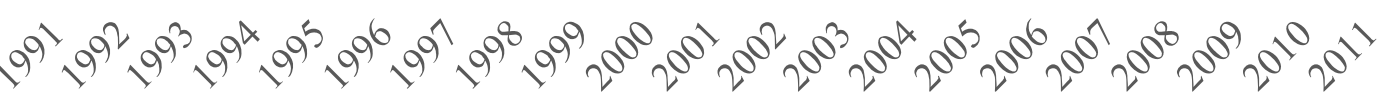

up to $2006-$ up to $2008 \cdots$ up to 2010

up to 2012 ..... up to $2014 \longrightarrow$ up to 2016 
Regarding the IGE, estimated elasticities are slightly higher when using more years of data, presumably due to lower measurement error, but the graphs move very much in tandem. The lowest correlation over the years 1991-2001 is between the 2006 and 2016 estimates, and equals 0.88 . The close correspondence between the trends estimated for the eleven oldest cohort groups from data to 2006 and the estimates derived from all available data to 2016, suggests that the trends estimated from current data for the youngest ten cohort groups should similarly hold up when further data is available in future. The correspondence for the IRC appears even closer, with the six similarly constructed graphs in the bottom panel nearly indistinguishable. The correlation between the 2006 and 2016 graphs is 0.86 .

Next, we test the robustness of our measures to sampling in the first stage. In each of 100 repetitions, we randomly draw a 50\% subsample (with replacement) from our "males sample" and use it to estimate equation (1). The estimated fixed effects are our lifetime income proxies for all individuals in the $50 \%$ subsample, and for the remaining males our proxy for lifetime income for an individual is the average difference between predicted and actual income over all income observations for that individual. We then use these proxies for lifetime income in the second stage. The two panels of Figure 8 present our results for the IGE and IRC. They show the mean IGE and IRC from 100 repetitions, with 95\% ranges of estimates. The means closely follow our full estimation with relative differences of less than 0.006 for the IGE and 0.002 for the IRC, and narrow $95 \%$ ranges of less than 0.05 on average for both measuresslightly narrower in the middle, slightly wider in the earlier and later years. 
Figure 8. Mean IGE and IRC with 95\% range, sons aged 30-39, 100 repetitions. In each repetition, we drew a 50\% subsample with replacements to estimate the first stage.

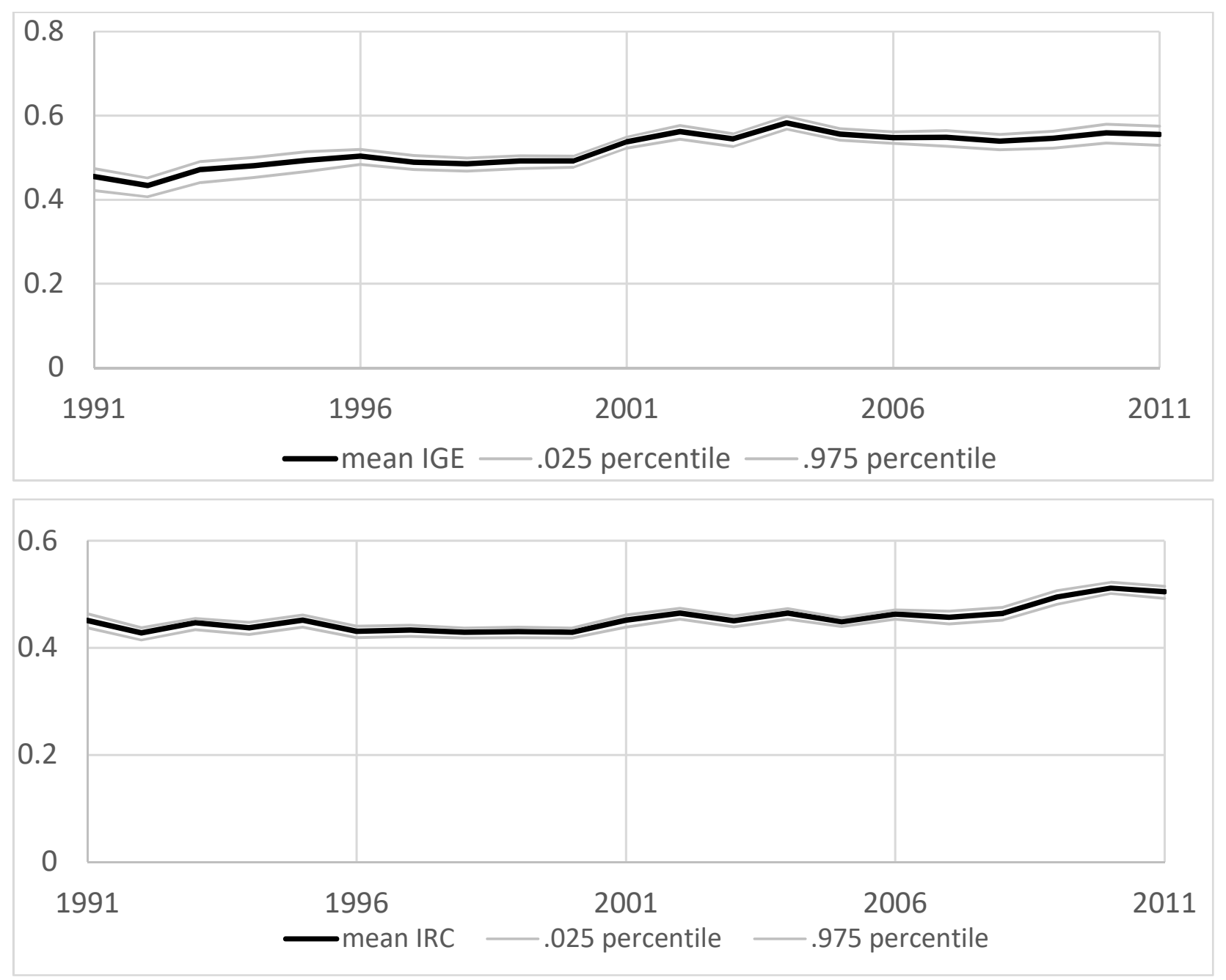

\section{Applying our first-stage analysis to adjust snapshot data}

Recent research on trends in intergenerational mobility has increasingly focused on large-scale administrative population data, from tax records or social security files. It has obvious advantages in terms of representativeness, compared to panel data that is invariably vulnerable to sample bias. However, the large majority of these administrative datasets still have relatively short usable histories, which particularly constrain their application to estimating trends in intergenerational mobility reliably. Because of their short histories they typically follow single cohorts of sons or daughters at a fixed age over time, focusing on the rank correlation (or other 
mobility metric) between their income (or earnings) at that age and their parents' income while they were growing up, possibly averaging parents' income over a few years. Recent work by Nybom and Stuhler $(2016,2017)$, building on the earlier work of Haider and Solon (2006), Grawe (2006) and Hertz (2007), indicates that mobility estimates based on annual snapshots of children's income, typically when children are around 30 years old, are sensitive to substantial attenuation error that exaggerates the extent of intergenerational mobility. ${ }^{19}$ As the slope of the age-income gradient varies markedly with education (Appendix Figure A2), income at age 30 is a noisy indicator of lifetime income (Figure 1 and Table 1 above).

The following illustrative analysis indicates how our first-stage analysis can be applied to derive more accurate estimates of IRC trends from single-year snapshots of children's income aged around 30, when it can be combined with individual data on education, race and marital status. ${ }^{20}$ To illustrate this, we construct a subsample of father-son pairs for which we have at least one positive income observation for the son between the ages of 29 and 31; and at least three positive observations for the father when the son was aged between 15 and 19 . For these we compare IRCs derived from snapshot averages, IRCs from our lifetime income

${ }^{19}$ The relatively young age at which children are observed in these studies is again dictated by the historical depth of the available administrative data sets and by the need to also observe parents' income.

${ }^{20}$ Our focus on the IRC follows Chetty et al.'s (2014a, 2014b) focus on rank-rank correlations, and indeed our snapshot estimates are similar in magnitude to those Chetty et al. (2104a) obtain in their trend analysis. The IRC is less sensitive to the use of snapshot data than the IGE. In our data, IGE trends from snapshot data are negatively correlated with IGE trends from lifetime incomes, and our adjustment offers little improvement. 
estimates, ${ }^{21}$ and IRCs derived from adjusted snapshot incomes, obtained by combining snapshot income data with our first-stage coefficient estimates, from equation (1), for sons and fathers. Specifically, these are the individual fixed effects that maximize the fit of equation (1) to observed income in years when snapshot income data is available. Figure 9 compares these three time-series of IRC estimates, marked respectively "snapshot data", "lifetime income" and adjusted data.

Figure 9. IRC estimates for 21 rolling ten-year cohort groups based on lifetime income, snapshot data and adjusted snapshot data

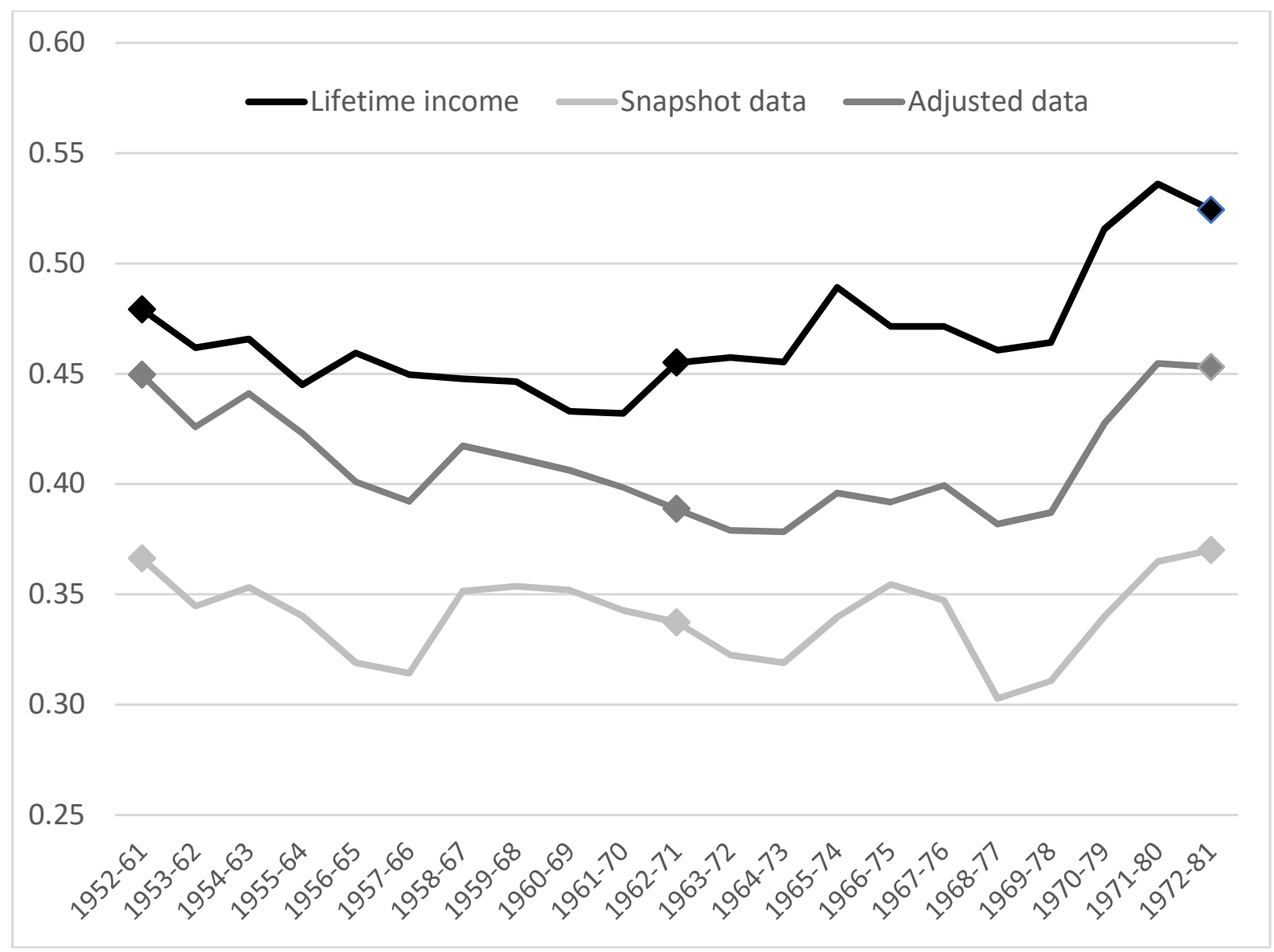

${ }^{21}$ They are very similar but not identical to Figure 5 due to slightly different selection criteria. 
The adjusted estimates are closer in level to the lifetime-income estimates based on full income histories, than the snapshot data estimates-closing more than half the gap, on average - and more closely correlated with the lifetime-income estimates. The correlation of the lifetime-income estimates with the snapshot data is 0.39 , and with the adjusted data, 0.58 . This is only an illustrative example-large administrative data sets have different properties and may well behave differently_ but it does indicate that where individual socio-economic covariates are available, using them to adjust snapshot income data along these lines can improve the accuracy of mobility estimates.

\section{Conclusion}

In this paper, we present a two-stage approach to estimating intergenerational income mobility that first explicitly estimates parents' and children's average lifetime family income, and then uses these estimates to derive a range of mobility measures. This directly addresses the sensitivity of previous estimates, based on snapshot measures of annual income, to attenuation error associated with the age income is measured, and reduces measurement error in both parents' and children's income. This more efficient use of incomplete income histories allows us, in particular, to derive reliable estimates of the intergenerational mobility of more recent cohorts for whom income histories are necessarily shorter.

Applying this approach to data from the United States PSID, for sons born between 1952 and 1981, and their fathers, we first estimate fathers' and sons' average lifetime family income from linked longitudinal income data and background variables on education, race and marital status. We then show the close fit of our estimates to actual lifetime income averages for a subsample of males for whom longer income histories are available, contrasting it with the much poorer fit of annual income around age 30, and the slightly poorer fit obtained by averaging fathers' income when sons were aged 13-17. The second stage then uses these 
estimates to derive measures of absolute, relative and rank mobility for three disjoint ten-year cohort-groups, 1952-61, 1962-71 and 1972-81, and follow the gradual change of some of these measures over 21 rolling ten-year cohort-groups. Averaging these measures over a ten-year range of sequential cohorts addresses much — though not all—of the ambiguity of relating cohort-based mobility measures to calendar time. The measures we derive include the share of sons earning more than their fathers; the (non-anonymous) intergenerational distributional incidence of income growth; indices of intergenerational mobility as dynastic income equalization; the intergenerational correlation of income; the intergenerational elasticity of income (IGE); the conditional median; the inter-quartile mobility matrix; and average and localized values of the intergenerational rank correlation (IRC) of income.

Our findings on absolute upward mobility shares are generally consistent with previous comparable research. We find a moderate decline in absolute upward mobility for our youngest cohort-group, with slightly lower levels than previously found, possibly because our income measure is more forward-looking. We find that intergenerational income growth has been substantially progressive: where fathers in the quartile of their income distribution have incomes more than three times the income of fathers in the bottom quartile, their sons' incomes are less than twice the incomes of sons of fathers in the bottom quartile. We estimate the intergenerational elasticity of family income, for recent cohorts, at about 0.55 , consistent with the higher values advocated by Mazumder $(2016,2018)$ and Mitnik et al. (2017), and find multiple indications that relative intergenerational income mobility has declined moderately over this period. Simultaneous estimation of cohort-group specific IGEs and sons' lifetime income allows us to test the statistical significance of the increase in the IGE from the oldest to the youngest cohort, yielding a $p$-value of 0.06 , implying a significant decline in mobility.

With regard to positional mobility, inter-quartile transitional matrices reveal that the ends of the distribution — the highest and lowest quartiles — are, not surprisingly, "stickier" than 
the middle, as earlier studies have also found. The conditional probabilities of a son born into the highest income quartile remaining in the highest quartile, or of a son born onto the lowest quartile remaining in the lowest quartile, range from $40 \%$ to $52 \%$, where the corresponding probabilities for the middle quartiles are much lower. Localized rank-rank correlations have remained stable in the three middle quintiles of fathers' income distribution, with a slope of about 0.48 for all three cohort-groups, but changes at the top and bottom quintiles induced a slight decline in average positional mobility estimated over the full range of incomes, with a value of 0.51 for our youngest cohort-group. Overall, we find multiple indications of a moderate decline in father-son mobility in lifetime family income in the United States over this period in most but not all dimensions.

Moreover, we show that these estimates are dynamically stable to the addition of new waves of data, supporting our claim that they provide reliable estimates for younger cohorts, too; and that they are robust to $50 \%$ sampling of individuals in the first stage. Finally, we illustrate how the accuracy of estimated trends in the IRC based on single-year snapshot income data can be improved, when background data on education, race and marital status are available. Our first-stage coefficient estimates can then be used to derive adjusted income measures that more closely approximate IRCs estimated from lifetime income. 


\section{Acknowledgments}

This paper draws on earlier cited work with Anna Krush. It has benefited from comments on earlier versions by Richard Burkhauser, Francois Bourguignon, Danny Cohen-Zada, Gary Fields, Mark Gradstein, Chris Ryan, Jacques Silber and seminar participants at Ben Gurion University and the University of Melbourne, and participants in the Ecineq annual meetings in New York and Paris. Financial support from Ben Gurion University and Ruppin Academic College are gratefully acknowledged.

\section{References}

Aaronson, D and B Mazumder, 2008. Intergenerational economic mobility in the United States, 1940 to 2000. Journal of Human Resorces 41(1):139-172.

Acs, G, D Elliott and E Kalish. 2016. What would substantially increased mobility from poverty look like? Working Paper. The Urban Institute.

Bengali, L and M Daly. 2013. US economic mobility: The dream and the data. Federal Reserve Bank of San Francisco Economic Letter 2013:06.

Bourguignon, F, 2010. Non-anonymous growth incidence curves, income mobility and social welfare dominance. Journal of Economic Inequality 9:605-627.

Chetty, R, N Hendren, P Kline, E Saez and N Turner, 2014a. Is the United States still a land of opportunity? Recent trends in intergenerational mobility. American Economic Review: Papers and Proceedings 104(5):141-147. 
Chetty, R, N Hendren, P Kline and E Saez. 2014b. Where is the land of opportunity? The geography of intergenerational mobility in the United States. Quarterly Journal of Economics 129: 1553-1623.

Chetty, R, D Grusky, M Hell, N Hendren, R Manduca and J Narang, 2017. The fading American dream: Trends in absolute income mobility since 1940. Science 356, 398406.

Durlauf, S, A Kourtellos and C Tan, 2017. Status traps. Journal of Business and Economic Statistics 35:265-287.

Fields, G, 2010. Does income mobility equalize longer-term incomes? New measures of an old concept. Journal of Economic Inequality 8:409-427.

Fields G, 2006. The many facets of economic mobility. In Inequality, Poverty and Well-being, pp. 123-142. Palgrave Macmillan, London.

Fields, G and E Ok, 1996. The meaning and measurement of income mobility. Journal of Economic Theory 71:349-377.

Grawe, N, 2006. Lifecycle bias in estimates of intergenerational earnings persistence. Labour economics, 13: 551-570.

Guvenen, F, G Kaplan, J Song and J Weidner, 2017. Lifetime incomes in the United States over six decades. WP 23371. National Bureau of Economic Research.

Haider, S and G Solon, 2006. Life-cycle variation in the association between current and lifetime earnings. American Economic Review 96:1308-1320.

Halikias, B and R Reeves, 2016. How many people are better off than their parents? Depends on how you cut the data. Brookings Institution. 
Hertz, T, 2007. Trends in the intergenerational elasticity of family income in the United States. Industrial Relations 46:22-50.

Isaacs, J, 2007. Economic mobility of families across generations. Economic Mobility Project, Brookings Institution and Pew Charitable Trusts.

Jäntti, M and S Jenkins, 2015. Income mobility. In A Atkinson and F Bourguignon, eds., Handbook of Income Distribution, v. 2, pp. 807-935. Elsevier-North Holland.

Justman, M and A Krush, 2013. Less equal and less mobile: Evidence of a decline in intergenerational income mobility in the United States. WP 43/13, Melbourne Institute of Applied Economic and Social Research, University of Melbourne.

Lee, C-I and G Solon, 2006. Trends in intergenerational income mobility. WP 12007 National Bureau of Economic Research.

Lee, C-I and G Solon, 2009. Trends in intergenerational income mobility. Review of Economics and Statistics 91:766-772.

Mayer, S and L Lopoo, 2005. Has the intergenerational transmission of economic status changed? Journal of Human Resources 40:169-185.

Mazumder, B, 2005. Fortunate sons: new estimates of intergenerational mobility in the U.S. using social security earnings data. Review of Economics and Statistics 87(2):235-55.

Mazumder, B, 2016. Estimating the intergenerational elasticity and rank association in the United States: Overcoming the current limitations of tax data. In Inequality: Causes and Consequences, pp. 83-129. Emerald Group Publishing Limited. 
Mazumder, B, 2018. Intergenerational income mobility in the US: What we have learned from the PSID. Annals of the American Academy of Political and Social Science, 680(1), 213-234. https://doi.org/10.1177/0002716218794129

Mitnik, P, V Bryant and M Weber, 2018. The intergenerational transmission of family-income advantages in the United States. Stanford Center on Poverty and Inequality Working Paper.

Nybom, M and J Stuhler, 2016. Heterogeneous income profiles and lifecycle bias in intergenerational mobility estimation. Journal of Human Resources 51: 239-268.

Nybom, M and J Stuhler, 2017. Biases in standard measures of intergenerational income dependence. Journal of Human Resources 52: 800-825.

Shorrocks, A, 1978. Income inequality and income mobility, Journal of Economic Theory 19: 376-393.

Solon, G, 1992. Intergenerational income mobility in the United States. American Economic Review 82: 393-408.

United States Census Bureau, 2019a. Historical income tables. Table A1. Retrieved Jan 2019 from: https://www2.census.gov/programs-surveys/demo/tables/p60/259/tableA1.xls

United States Census Bureau, 2019b. Historical income tables: Income inequality, Table A2. Retrieved January 2019 from: http:/www.census.gov/data/tables/timeseries/demo/income-poverty/ historical-income-households.html . 


\section{Appendix Figures}

Figure A1. Estimates of intergenerational elasticity (IGE), between sons aged 30-39 and their fathers, using sons' predicted income at age 40 and fathers' predicted income at ages 40 and 45.

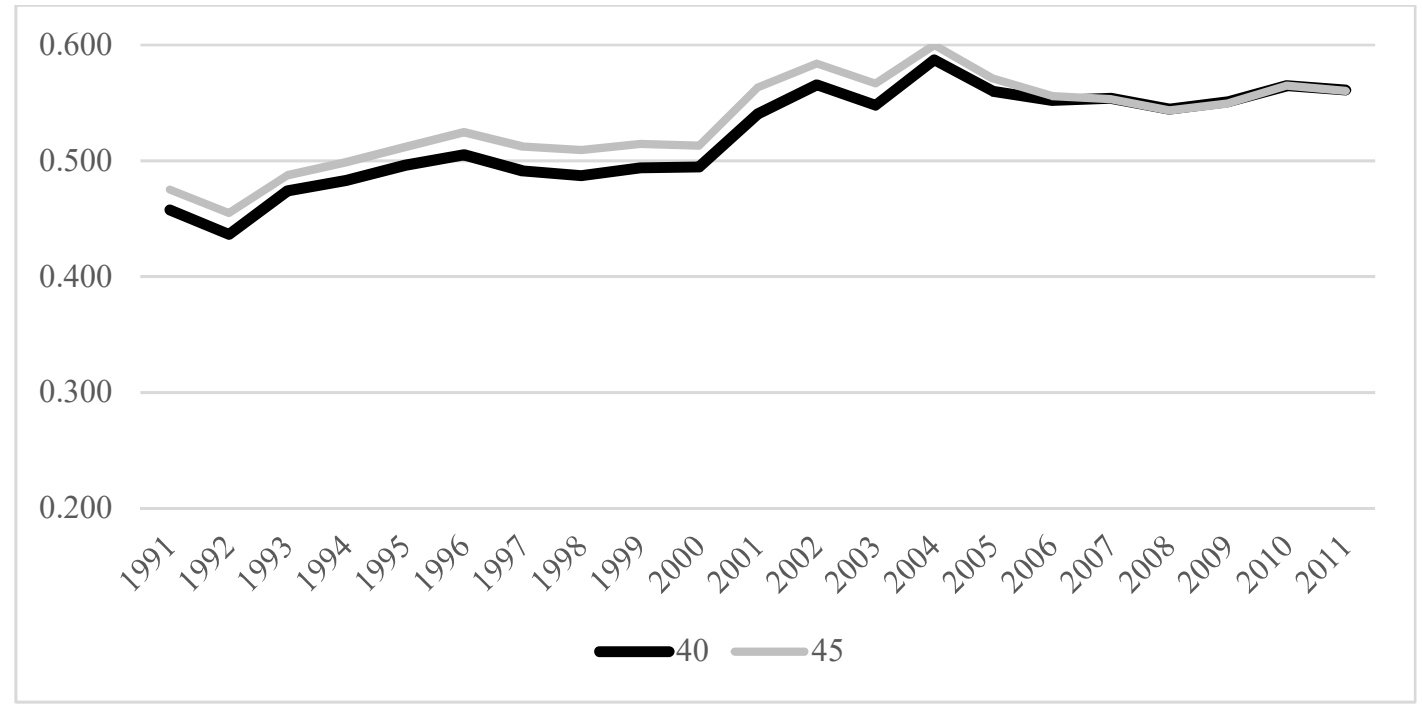

Note: Predicted income at ages 40 and 45 derived from a regression of all income observations on age and age squared, and their interaction with education, race and marital status (equation 1).

Figure A2. Two age-income profiles, by years of schooling, married white males

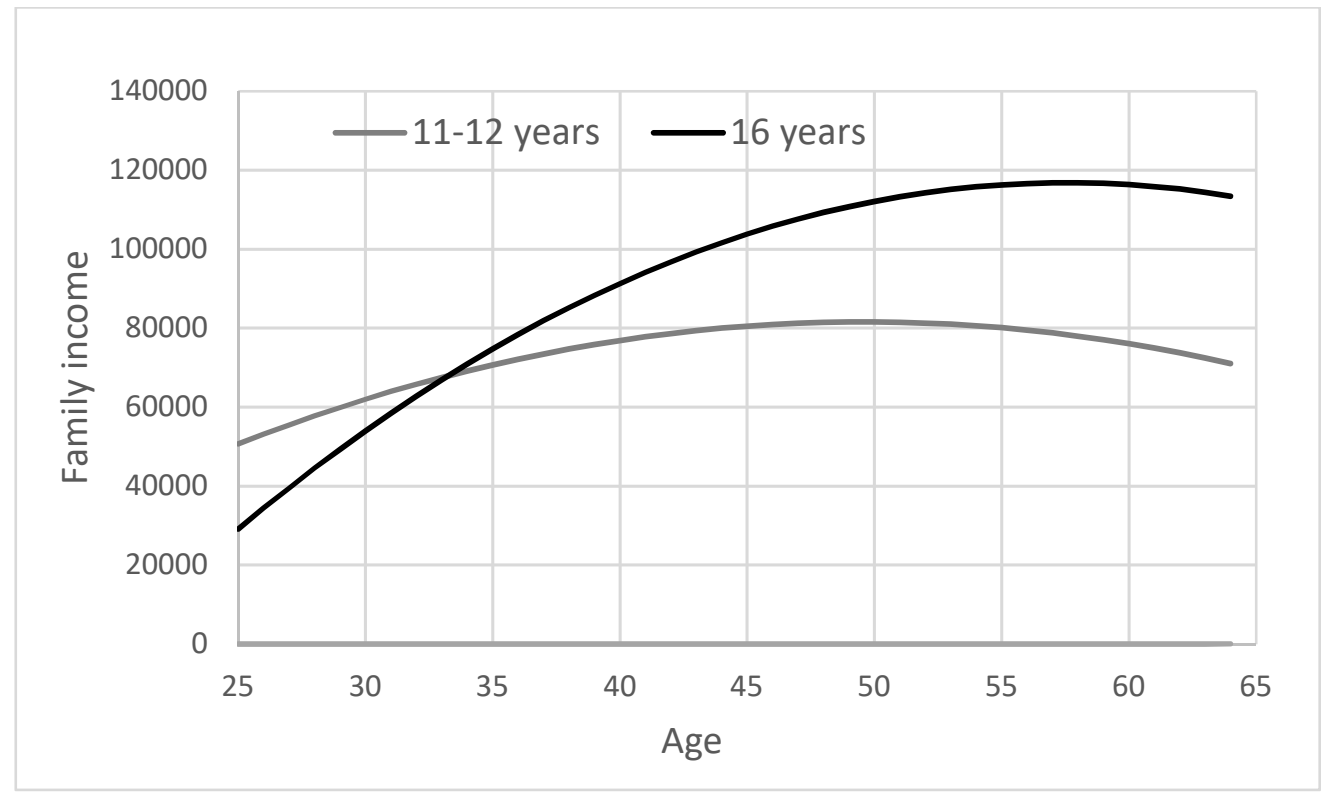

Note: Shape of age-income profiles derived from a regression of all income observations on age and age squared, and their interaction with education, race and marital status (equation 1). Individual fixed effects chosen to demonstrate a rank reversal in income between ages 30 and 40 . 
Figure A3. Comparison of estimates of the IGE of family income between sons aged 30-39 and their fathers, when the first-stage age-income profile is fixed over time and when it is allowed to vary.

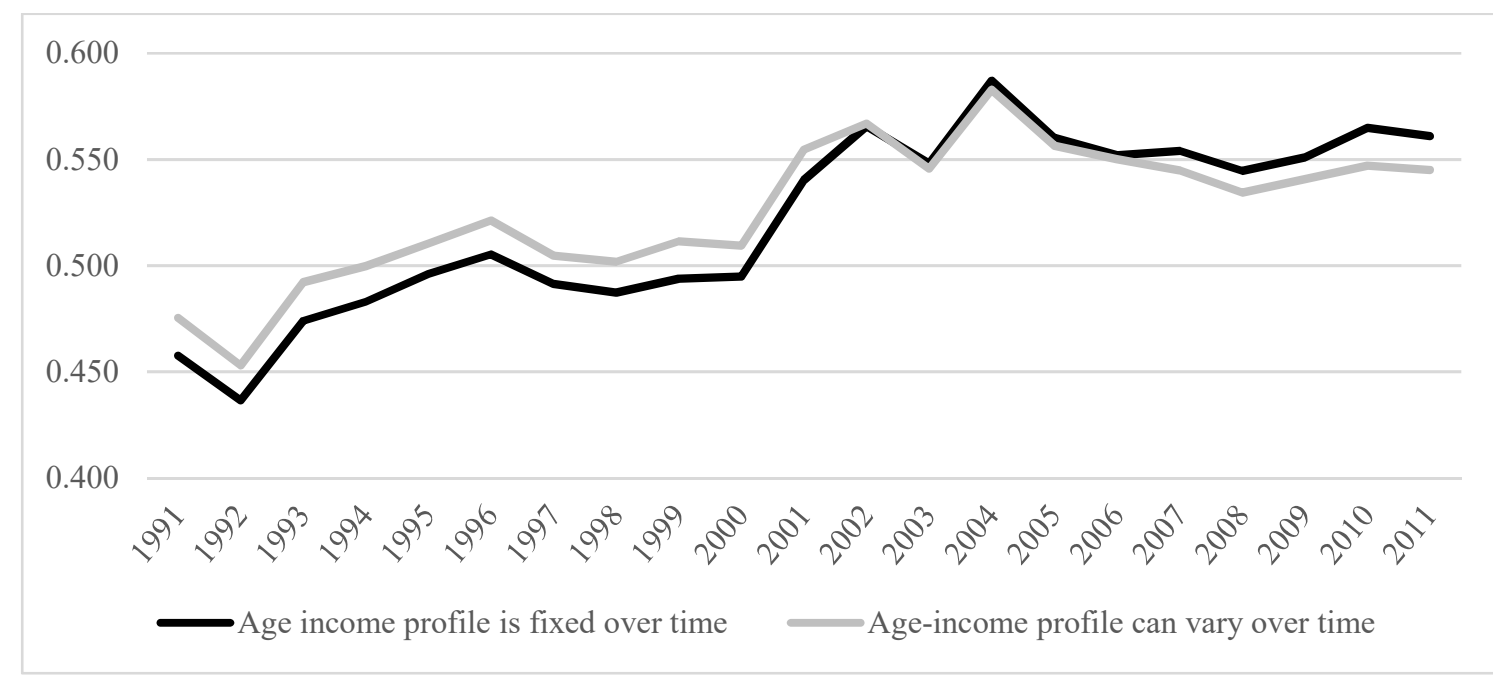

Note: "Age-income profile is fixed over time" is the IGE graph in Figure 3. "Age-income profile can vary over time" is an IGE series estimated using lifetime income from a first stage in which we allow the age-income profiles conditioned on background variables to vary over time. Specifically, we divide the male sample into nine overlapping cohort groups of roughly equal size, and estimate individuals' lifetime income from equation 1 within each group. Because of the overlap, some individuals have two predicted values of lifetime income, and we take their average. 
Figure A4. Mean annual family income and the Gini coefficient of annual family income, 1967 to 2016, our pairs sample compared to national United States data; each data point represents a year.
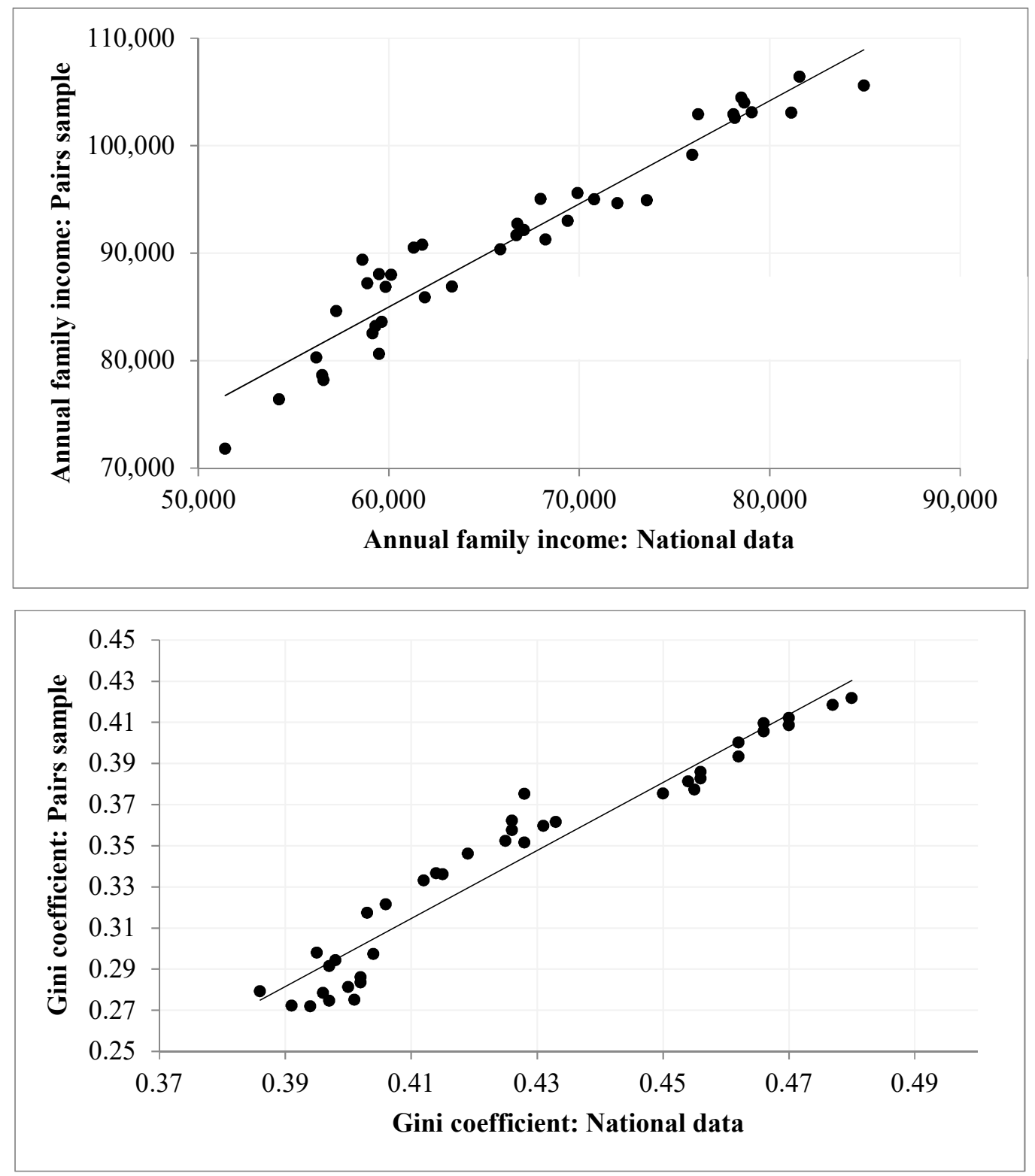

Pairs sample from the PSID, authors' calculations; national data from US Census Bureau (2019b). 
Figure A5. Fathers' and sons' average lifetime family income, by sons' cohort group, 2010 dollars, with $45^{\circ}$ lines
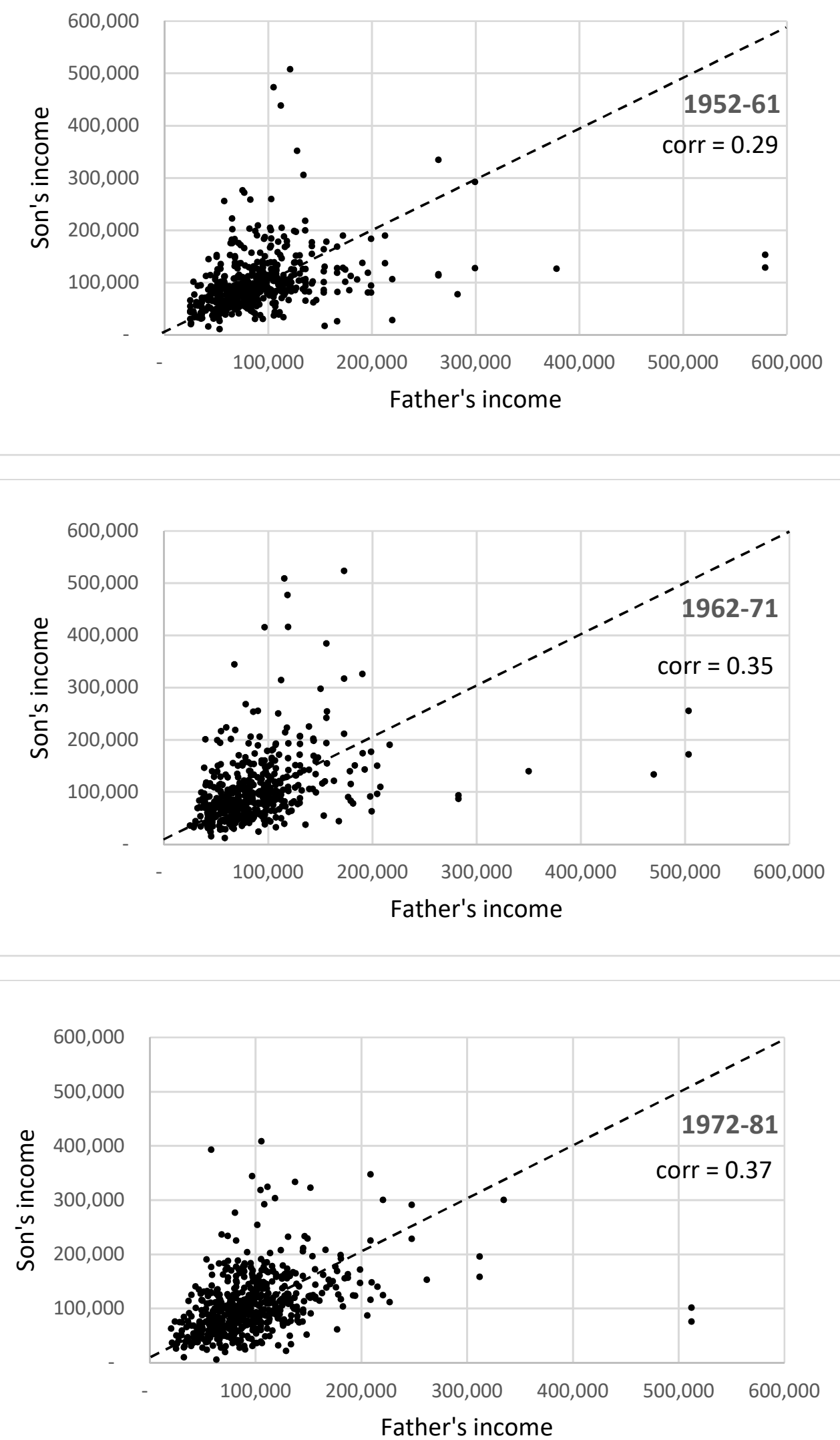
Figure A6. Three estimates of intergenerational income elasticities from PSID data

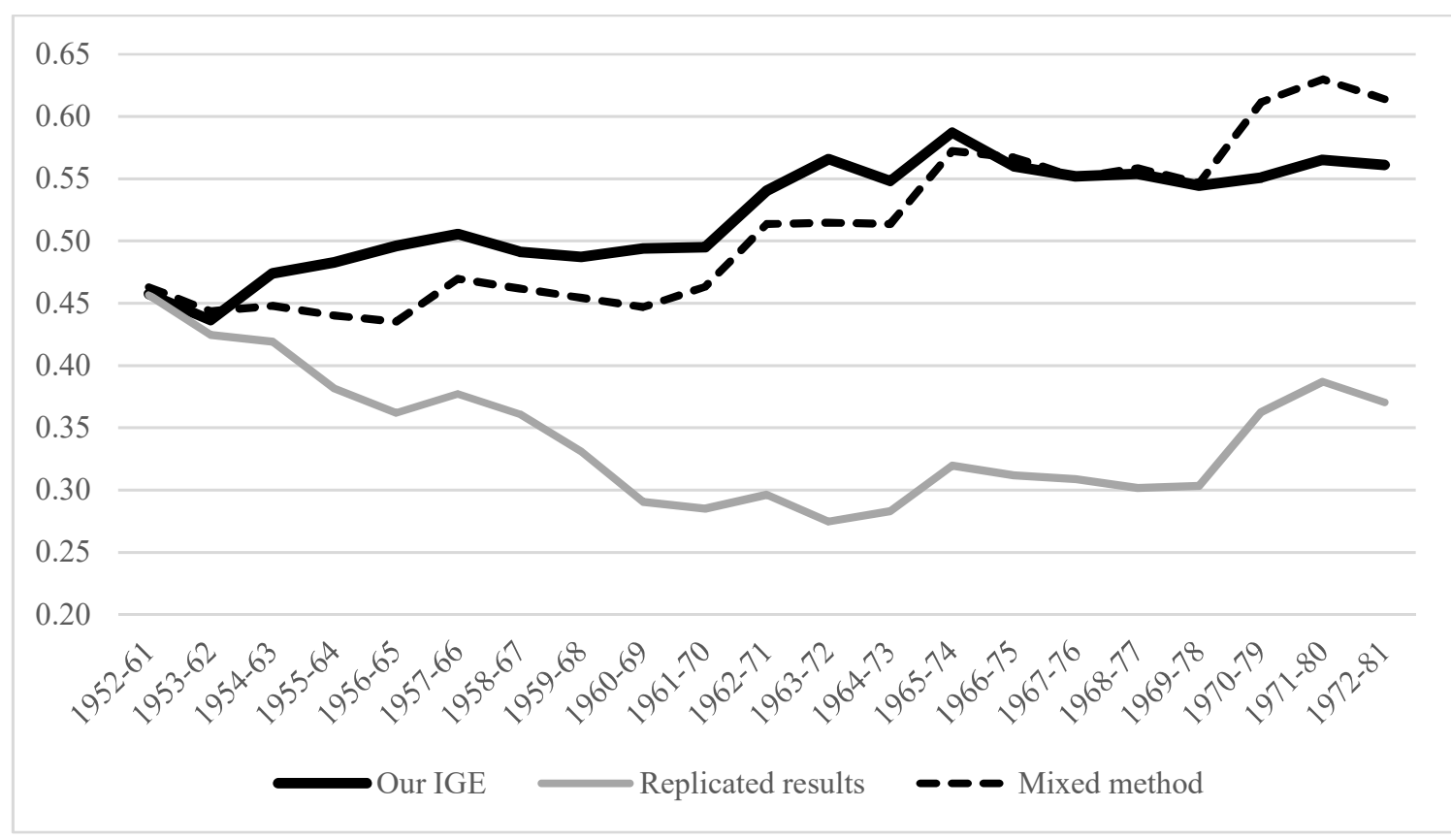

Note: "Our IGE" is the IGE graph in Figure 3. "Replicated results" applies Durlauf et al.'s (2017) method to our data: averaging sons' actual income between the ages of 25 and 34, and fathers' actual income when the son is aged 13 to 17. "Mixed method" uses their method for sons' income and our method for fathers' income.

Figure A7. Quadratic local approximation of IGE regressions, by sons' cohort-group, using Stata's LOWESS procedure

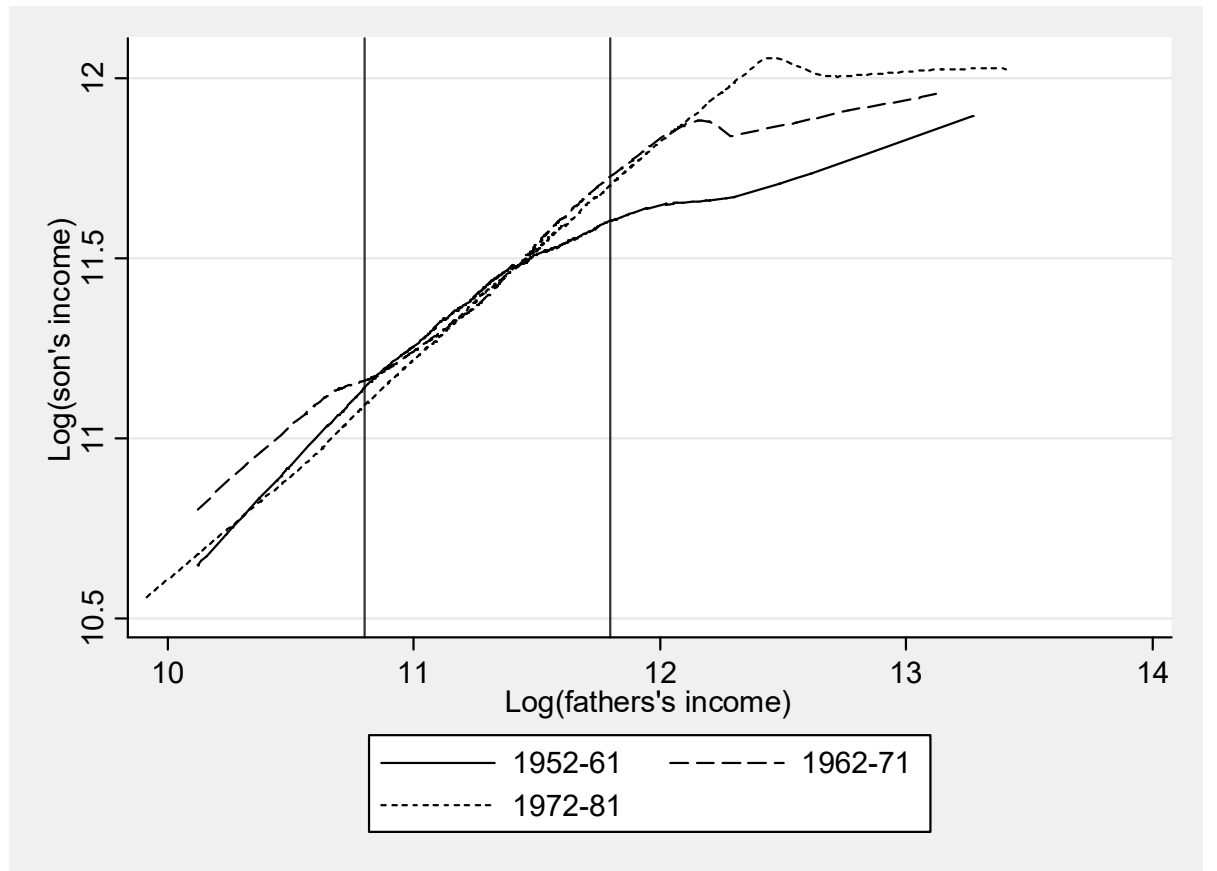

Note: Vertical lines indicate the $10^{\text {th }}$ and $90^{\text {th }}$ percentiles. 


\section{Appendix Tables}

Table A1. First-stage estimation results

Coefficient Standard error

\begin{tabular}{|c|c|c|c|}
\hline & $\begin{array}{l}\text { Age } \\
\text { Age*Age }\end{array}$ & $\begin{array}{c}-927.6^{*} \\
6.471\end{array}$ & $\begin{array}{l}552.5 \\
26.50\end{array}$ \\
\hline \multirow{6}{*}{$\begin{array}{l}\text { Age interactions } \\
\text { with race }\end{array}$} & Age*White & $744.3 * * *$ & 246.9 \\
\hline & Age*Age*White & $-76.80 * * *$ & 14.89 \\
\hline & Age*Afro-American & -64.10 & 264.5 \\
\hline & Age*Age*Afro-American & $-48.24 * * *$ & 16.34 \\
\hline & Age*Latino-American & $501.9^{*}$ & 293.9 \\
\hline & Age*Age*Latino-American & $-81.83 * * *$ & 18.07 \\
\hline \multirow{10}{*}{$\begin{array}{l}\text { Age interactions with } \\
\text { years of schooling }\end{array}$} & Age $^{*}$ Age $^{*}<8$ & $33.85 * *$ & 15.91 \\
\hline & Age*8-10yrs & 227.1 & 307.1 \\
\hline & Age $^{*} 11-12 \mathrm{yrs}$ & 364.8 & 284.0 \\
\hline & Age*Age*11-12yrs & 7.135 & 7.524 \\
\hline & Age*13-15yrs & $926.7 * * *$ & 285.1 \\
\hline & Age*Age*13-15yrs & 3.871 & 7.750 \\
\hline & Age*16yrs & $2,289 * * *$ & 287.0 \\
\hline & Age*Age*16yrs & $-24.44 * * *$ & 8.063 \\
\hline & Age $^{*}>16 y r s$ & $3,483 * * *$ & 286.4 \\
\hline & Age*Age* $>16$ yrs & $-83.16^{* * *}$ & 7.910 \\
\hline \multirow{9}{*}{$\begin{array}{l}\text { Age interactions with } \\
\text { marital status }\end{array}$} & Age*Married & $799.4^{*}$ & 415.7 \\
\hline & Age*Age* Married & 12.07 & 21.21 \\
\hline & Age*Never married & 466.3 & 425.2 \\
\hline & Age*Age* Never married & $-99.33 * * *$ & 22.22 \\
\hline & Age* Divorced & 321.9 & 425.8 \\
\hline & Age*Age* Divorced & $-78.29 * * *$ & 21.97 \\
\hline & Age* Separated & 240.2 & 435.8 \\
\hline & Age*Age* Separated & $-38.66^{*}$ & 22.97 \\
\hline & Constant & $97,213 * * *$ & 235.7 \\
\hline
\end{tabular}

Estimation over $N=96,753$ annual income observations includes fixed effects for 7,510 individuals. $\quad R^{2}=0.617$. Significance: $* * * p<0.01, * * p<0.05, * p<0.1$ 
Table A2. Mean number and mean age of income observations by ten-year cohort group

\begin{tabular}{|c|c|c|c|c|c|c|}
\hline \multirow{3}{*}{$\begin{array}{c}\text { Sons' } \\
\text { year of } \\
\text { birth }\end{array}$} & \multirow[b]{3}{*}{$\begin{array}{c}\text { Year } \\
\text { sons are } \\
30-39\end{array}$} & \multirow[b]{3}{*}{$N$} & \multirow{2}{*}{\multicolumn{2}{|c|}{ Fathers }} & \multirow{2}{*}{\multicolumn{2}{|c|}{ Sons }} \\
\hline & & & & & & \\
\hline & & & $\begin{array}{c}\text { Mean } \\
\text { number of } \\
\text { observations }\end{array}$ & $\begin{array}{c}\text { Mean age of } \\
\text { observed } \\
\text { income }\end{array}$ & $\begin{array}{c}\text { Mean } \\
\text { number of } \\
\text { observations }\end{array}$ & $\begin{array}{c}\text { Mean age of } \\
\text { observed } \\
\text { income }\end{array}$ \\
\hline $1952-61$ & 1991 & 477 & 23 & 50 & 20 & 37 \\
\hline $1953-62$ & 1992 & 477 & 24 & 50 & 19 & 37 \\
\hline $1954-63$ & 1993 & 484 & 24 & 49 & 19 & 37 \\
\hline $1955-64$ & 1994 & 484 & 25 & 49 & 18 & 36 \\
\hline $1956-65$ & 1995 & 477 & 26 & 48 & 17 & 36 \\
\hline $1957-66$ & 1996 & 456 & 26 & 47 & 16 & 36 \\
\hline $1958-67$ & 1997 & 496 & 27 & 47 & 15 & 35 \\
\hline $1959-68$ & 1998 & 487 & 27 & 46 & 15 & 35 \\
\hline $1960-69$ & 1999 & 492 & 28 & 46 & 14 & 35 \\
\hline $1961-70$ & 2000 & 474 & 28 & 45 & 13 & 35 \\
\hline $1962-71$ & 2001 & 468 & 29 & 44 & 12 & 35 \\
\hline $1963-72$ & 2002 & 478 & 28 & 44 & 12 & 35 \\
\hline $1964-73$ & 2003 & 485 & 28 & 43 & 11 & 34 \\
\hline $1965-74$ & 2004 & 485 & 28 & 43 & 10 & 34 \\
\hline $1966-75$ & 2005 & 492 & 28 & 42 & 10 & 34 \\
\hline $1967-76$ & 2006 & 515 & 27 & 42 & 9 & 34 \\
\hline $1968-77$ & 2007 & 498 & 27 & 41 & 9 & 33 \\
\hline $1969-78$ & 2008 & 523 & 26 & 41 & 8 & 33 \\
\hline $1970-79$ & 2009 & 542 & 26 & 41 & 8 & 33 \\
\hline $1971-80$ & 2010 & 568 & 25 & 41 & 7 & 33 \\
\hline 1972-81 & 2011 & 591 & 25 & 41 & 7 & 32 \\
\hline
\end{tabular}


Table A3. Fathers' and sons' estimated lifetime family income, by cohort-group, 2010 dollars

\begin{tabular}{|c|c|c|c|c|c|c|c|c|c|}
\hline \multirow{3}{*}{$\begin{array}{l}\text { Sons' year } \\
\text { of birth }\end{array}$} & \multirow{3}{*}{$\begin{array}{c}N \\
\text { pairs }\end{array}$} & \multicolumn{4}{|c|}{ Fathers } & \multicolumn{4}{|c|}{ Sons } \\
\hline & & \multirow{2}{*}{$\begin{array}{c}\text { Mean } \\
\text { predicted } \\
\text { average } \\
\text { lifetime } \\
\text { income* }\end{array}$} & \multirow{2}{*}{$\begin{array}{c}1- \\
\text { SSe/ } \\
n^{*} \text { Var }\end{array}$} & \multicolumn{2}{|c|}{$\begin{array}{l}\text { Log (predicted average } \\
\text { lifetime income) }\end{array}$} & \multirow{2}{*}{$\begin{array}{c}\text { Mean } \\
\text { predicted } \\
\text { average } \\
\text { lifetime } \\
\text { income* }\end{array}$} & \multirow{2}{*}{$\begin{array}{c}1- \\
\text { SSe/ } \\
n^{*} \text { Var }\end{array}$} & \multicolumn{2}{|c|}{$\begin{array}{c}\text { Log (predicted average } \\
\text { lifetime income) }\end{array}$} \\
\hline & & & & Mean & $\begin{array}{l}\text { Standard } \\
\text { deviation }\end{array}$ & & & Mean & $\begin{array}{l}\text { Standard } \\
\text { deviation }\end{array}$ \\
\hline $1952-61$ & 477 & 92,127 & 0.552 & 11.311 & 0.476 & 101,251 & 0.618 & 11.400 & 0.503 \\
\hline $1953-62$ & 477 & 92,756 & 0.540 & 11.319 & 0.473 & 101,336 & 0.611 & 11.406 & 0.495 \\
\hline $1954-63$ & 484 & 92,052 & 0.543 & 11.312 & 0.471 & 102,680 & 0.611 & 11.413 & 0.505 \\
\hline $1955-64$ & 484 & 91,737 & 0.553 & 11.311 & 0.469 & 103,757 & 0.597 & 11.418 & 0.511 \\
\hline $1956-65$ & 477 & 93,135 & 0.565 & 11.320 & 0.472 & 103,920 & 0.596 & 11.414 & 0.518 \\
\hline $1957-66$ & 456 & 91,191 & 0.584 & 11.309 & 0.451 & 103,884 & 0.578 & 11.409 & 0.530 \\
\hline $1958-67$ & 496 & 91,897 & 0.595 & 11.311 & 0.459 & 104,672 & 0.601 & 11.411 & 0.537 \\
\hline $1959-68$ & 487 & 90,797 & 0.599 & 11.301 & 0.453 & 104,195 & 0.602 & 11.407 & 0.534 \\
\hline $1960-69$ & 492 & 91,064 & 0.595 & 11.299 & 0.465 & 105,460 & 0.595 & 11.417 & 0.542 \\
\hline $1961-70$ & 474 & 90,484 & 0.597 & 11.302 & 0.45 & 106,026 & 0.577 & 11.429 & 0.528 \\
\hline $1962-71$ & 468 & 90,360 & 0.607 & 11.306 & 0.438 & 106,012 & 0.576 & 11.422 & 0.538 \\
\hline $1963-72$ & 478 & 90,129 & 0.608 & 11.305 & 0.437 & 105,739 & 0.576 & 11.419 & 0.545 \\
\hline $1964-73$ & 485 & 90,908 & 0.618 & 11.313 & 0.438 & 105,198 & 0.580 & 11.416 & 0.539 \\
\hline $1965-74$ & 485 & 91,356 & 0.621 & 11.323 & 0.428 & 105,201 & 0.582 & 11.414 & 0.542 \\
\hline $1966-75$ & 492 & 91,169 & 0.619 & 11.325 & 0.427 & 105,601 & 0.575 & 11.423 & 0.539 \\
\hline $1967-76$ & 515 & 93,299 & 0.629 & 11.343 & 0.437 & 106,940 & 0.595 & 11.438 & 0.535 \\
\hline $1968-77$ & 498 & 93,950 & 0.638 & 11.350 & 0.439 & 106,704 & 0.576 & 11.442 & 0.530 \\
\hline $1969-78$ & 523 & 95,026 & 0.640 & 11.357 & 0.446 & 107,694 & 0.594 & 11.449 & 0.534 \\
\hline $1970-79$ & 542 & 96,581 & 0.637 & 11.363 & 0.461 & 107,041 & 0.638 & 11.448 & 0.526 \\
\hline $1971-80$ & 568 & 96,171 & 0.632 & 11.356 & 0.469 & 105,193 & 0.638 & 11.428 & 0.536 \\
\hline $1972-81$ & 591 & 97,105 & 0.646 & 11.367 & 0.469 & 106,291 & 0.632 & 11.439 & 0.535 \\
\hline
\end{tabular}

* Predicted average lifetime income is predicted annual income at age 40, from a regression of all income observations on age and age squared, and their interaction with education, race and marital status, and individual fixed effects (equation 1). 1 - SSe / $n *$ Var is the proportion of the variance in observed income explained by the first stage: SSe is the sum of squared residuals from the first stage for that cohort group; $\mathrm{n}$ is the number of income observations for that group; and Var is their variance. 
Table A4. Estimates of the intergenerational elasticity (IGE) and rank correlation (IRC) by rolling ten-year cohort-groups, correlations of log (income), and the son-to-father ratio of standard deviations in log (income)

\begin{tabular}{cccccccc}
\hline $\begin{array}{c}\text { Sons' year } \\
\text { of birth }\end{array}$ & $N$ & IGE & $\begin{array}{c}2^{\text {nd }} \text { stage } \\
\text { standard } \\
\text { errors }\end{array}$ & $\begin{array}{c}\text { Pearson } \\
\text { correlation } \\
\text { of log income }\end{array}$ & $\begin{array}{c}\text { Son/Father } \\
\text { ratio of log std } \\
\text { deviations }\end{array}$ & IRC & $\begin{array}{c}\text { OLS } \\
\text { standard } \\
\text { errors }\end{array}$ \\
\hline $1952-61$ & 477 & 0.458 & 0.044 & 0.432 & 1.057 & 0.453 & 0.041 \\
$1953-62$ & 477 & 0.437 & 0.044 & 0.417 & 1.047 & 0.430 & 0.041 \\
$1954-63$ & 484 & 0.474 & 0.044 & 0.442 & 1.072 & 0.449 & 0.041 \\
$1955-64$ & 484 & 0.483 & 0.045 & 0.443 & 1.090 & 0.440 & 0.041 \\
$1956-65$ & 477 & 0.496 & 0.045 & 0.452 & 1.097 & 0.454 & 0.041 \\
$1957-66$ & 456 & 0.505 & 0.050 & 0.430 & 1.175 & 0.433 & 0.042 \\
$1958-67$ & 496 & 0.491 & 0.048 & 0.420 & 1.170 & 0.434 & 0.041 \\
$1959-68$ & 487 & 0.487 & 0.049 & 0.414 & 1.179 & 0.430 & 0.041 \\
$1960-69$ & 492 & 0.494 & 0.048 & 0.424 & 1.166 & 0.431 & 0.041 \\
$1961-70$ & 474 & 0.495 & 0.049 & 0.422 & 1.173 & 0.429 & 0.042 \\
$1962-71$ & 468 & 0.540 & 0.051 & 0.440 & 1.228 & 0.452 & 0.041 \\
$1963-72$ & 478 & 0.566 & 0.051 & 0.454 & 1.247 & 0.465 & 0.041 \\
$1964-73$ & 485 & 0.548 & 0.050 & 0.446 & 1.231 & 0.450 & 0.041 \\
$1965-74$ & 485 & 0.587 & 0.051 & 0.463 & 1.266 & 0.464 & 0.040 \\
$1966-75$ & 492 & 0.560 & 0.051 & 0.444 & 1.262 & 0.449 & 0.040 \\
$1967-76$ & 515 & 0.552 & 0.048 & 0.451 & 1.224 & 0.463 & 0.039 \\
$1968-77$ & 498 & 0.554 & 0.048 & 0.459 & 1.207 & 0.458 & 0.040 \\
$1969-78$ & 523 & 0.545 & 0.047 & 0.455 & 1.197 & 0.465 & 0.039 \\
$1970-79$ & 542 & 0.551 & 0.043 & 0.483 & 1.141 & 0.495 & 0.037 \\
$1971-80$ & 568 & 0.565 & 0.042 & 0.495 & 1.143 & 0.513 & 0.036 \\
$1972-81$ & 591 & 0.561 & 0.041 & 0.492 & 1.141 & 0.506 & 0.036 \\
\hline
\end{tabular}

Note: "2 $2^{\text {nd }}$ stage standard errors" are the IGE standard errors estimated from the second-stage OLS regression of sons' logarithm of lifetime income on their fathers' logarithm of lifetime income. "OLS standard errors" are the IRC standard errors estimated from an OLS regression of the rank of sons' lifetime income on their fathers' ranks. 